\title{
Aerosol Property Retrieval Algorithm over Northeast Asia from TANSO-CAI Measurements Onboard GOSAT
}

\author{
Sanghee Lee ${ }^{1,2}$, Mijin Kim ${ }^{1}$, Myungje Choi ${ }^{1}$ (D), Sujung Go ${ }^{1}$, Jhoon Kim ${ }^{1,3, *}$ (D), \\ Jung-Hyun Kim ${ }^{1}$, Hyun-Kwang Lim ${ }^{1}$, Ukkyo Jeong ${ }^{1,4,5}$, Tae-Young Goo ${ }^{6}$, Akihiko Kuze ${ }^{7}$, \\ Kei Shiomi ${ }^{7}$ and Yokota Tatsuya ${ }^{8}$ \\ 1 Department of Atmospheric Science, Yonsei University, 50 Yonsei-ro, Seodaemun-gu, Seoul 03722, Korea; \\ sangheelee.atmos@gmail.com (S.L.); mysky0110@yonsei.ac.kr (M.K.); choi816@yonsei.ac.kr (M.C.); \\ myid0121@yonsei.ac.kr (S.G.); jhkim130@yonsei.ac.kr (J.-H.K.); raul105@yonsei.ac.kr (H.-K.L.); \\ Ukkyo.jeong@nasa.gov (U.J.) \\ 2 Meteorological Observation Laboratory, Weather Information Service Engine, Hankuk University of Foreign \\ Studies, Yongin-si, Gyeonggi-do 17035, Korea \\ 3 Harvard Smithsonian Center for Astrophysics, Cambridge, MA 02138, USA \\ 4 Goddard Space Flight Center, National Aeronautics and Space Administration, Greenbelt, MD 20771, USA \\ 5 Earth System Science Interdisciplinary Center, University of Maryland, College Park, MD 20740, USA \\ 6 Global Environment System Research Division, National Institute of Meteorological Sciences, Korea \\ Meteorological Administration, Jeju 63568, Korea; gooty@korea.kr \\ 7 Earth Observation Research Center, Japan Aerospace Exploration Agency, Tsukuba 305-8505, Japan; \\ kuze.akihilo@jaxa.jp (A.K.); shiomi.kei@jaxa.jp (K.S.) \\ 8 Center for Global Environmental Research, National Institute for Environmental Studies, Tsukuba 305-8505, \\ Japan; yoko@nies.go.jp \\ * Correspondence: jkim2@yonsei.ac.kr; Tel.: +82-2-2123-5682; Fax: +82-2-365-5163
}

Received: 19 April 2017; Accepted: 26 June 2017; Published: 5 July 2017

Abstract: The presence of aerosol has resulted in serious limitations in the data coverage and large uncertainties in retrieving carbon dioxide $\left(\mathrm{CO}_{2}\right)$ amounts from satellite measurements. For this reason, an aerosol retrieval algorithm was developed for the Thermal and Near-infrared Sensor for carbon Observation-Cloud and Aerosol Imager (TANSO-CAI) launched in January 2009 on board the Greenhouse Gases Observing Satellite (GOSAT). The algorithm retrieves aerosol optical depth (AOD), aerosol size information, and aerosol type in $0.1^{\circ}$ grid resolution by look-up tables constructed using inversion products from Aerosol Robotic NETwork (AERONET) sun-photometer observation over Northeast Asia as a priori information. To improve the accuracy of the TANSO-CAI aerosol algorithm, we consider both seasonal and annual estimated radiometric degradation factors of TANSO-CAI in this study. Surface reflectance is determined by the same 23-path composite method of Rayleigh and gas corrected reflectance to avoid the stripes of each band. To distinguish aerosol absorptivity, reflectance difference test between ultraviolet (band 1) and visible (band 2) wavelengths depending on AODs was used. To remove clouds in aerosol retrieval, the normalized difference vegetation index and ratio of reflectance between band $2(0.674 \mu \mathrm{m})$ and band $3(0.870 \mu \mathrm{m})$ threshold tests have been applied. To mask turbid water over ocean, a threshold test for the estimated surface reflectance at band 2 was also introduced. The TANSO-CAI aerosol algorithm provides aerosol properties such as AOD, size information and aerosol types from June 2009 to December 2013 in this study. Here, we focused on the algorithm improvement for AOD retrievals and their validation in this study. The retrieved AODs were compared with those from AERONET and the Aqua/MODerate resolution Imaging Sensor (MODIS) Collection 6 Level 2 dataset over land and ocean. Comparisons of AODs between AERONET and TANSO-CAI over Northeast Asia showed good agreement with correlation coefficient (R) $0.739 \pm 0.046$, root mean square error (RMSE) $0.232 \pm 0.047$, and linear regression line slope $0.960 \pm 0.083$ for the entire period. Over ocean, the comparisons between Aqua/MODIS and 
TANSO-CAI for the same period over Northeast Asia showed improved consistency, with correlation coefficient $0.830 \pm 0.047$, RMSE $0.140 \pm 0.019$, and linear regression line slope $1.226 \pm 0.063$ for the entire period. Over land, however, the comparisons between Aqua/MODIS and TANSO-CAI show relatively lower correlation (approximate $\mathrm{R}=0.67$, $\mathrm{RMSE}=0.40$, slope $=0.77$ ) than those over ocean. In order to improve accuracy in retrieving $\mathrm{CO}_{2}$ amounts, the retrieved aerosol properties in this study have been provided as input for $\mathrm{CO}_{2}$ retrieval with GOSAT TANSO-Fourier Transform Spectrometer measurements.

Keywords: AOD retrieval; GOSAT TANSO-CAI; reflectance difference method; radiometric degradation correction

\section{Introduction}

Aerosols and greenhouse gases (GHGs) such as carbon dioxide $\left(\mathrm{CO}_{2}\right)$ and methane $\left(\mathrm{CH}_{4}\right)$ are important factors in understanding climate change caused by anthropogenic activities [1] since the preindustrial period. Extensive satellite observations have been carried out to understand the global distribution of these particles and their changes. In particular, to reduce the uncertainty of $\mathrm{CO}_{2}$ amounts retrieved from satellite remote sensing, it is very important to have simultaneous, accurate aerosol information. To retrieve aerosol properties from satellites, there have been numerous studies based on the look-up table (LUT) approach [2-6] and optimal estimation theory [7-9].

To measure $\mathrm{CO}_{2}$ and $\mathrm{CH}_{4}$ concentrations, the Greenhouse Gases Observing Satellite (GOSAT) was launched on 23 January 2009 into sun-synchronous orbit at an altitude of $666 \mathrm{~km}$, at a local time of approximately 13:00 of descending node, and an inclination angle of $98^{\circ}[10,11]$. Thermal And Near-infrared Sensor for carbon Observation (TANSO), which is the observation instrument on board GOSAT, is composed of two subunits: a Fourier Transform Spectrometer (FTS) to measure GHGs and a Cloud and Aerosol Imager (CAI) to provide cloud and aerosol information simultaneously with FTS measurements [12]. The TANSO-CAI is a push-broom imager with one channel at ultraviolet (UV) band $1(0.37-0.39 \mu \mathrm{m})$, two channels at visible (VIS)-near infrared (NIR) bands 2 (0.664-0.684 $\mu \mathrm{m})$ and $3(0.86-0.88 \mu \mathrm{m})$, and one channel at short-wave infrared band $4(1.56-1.65 \mu \mathrm{m})$, as shown in Table $1[10,12]$.

Table 1. Characteristics of GOSAT TANSO-CAI channels used in the aerosol retrievals.

\begin{tabular}{ccccc}
\hline & Band 1 & Band 2 & Band 3 & Band 4 \\
\hline Spectral coverage $(\mu \mathrm{m})$ & $0.370-0.390(0.380)$ & $0.664-0.684(0.674)$ & $0.860-0.880(0.870)$ & $1.56-1.65(1.60)$ \\
Swath $(\mathrm{km})$ & 1000 & 1000 & 1000 & 750 \\
Spatial resolution at nadir $(\mathrm{km})$ & 0.5 & 0.5 & 0.5 & 1.5 \\
\hline
\end{tabular}

On 2 July 2014, the Orbiting Carbon Observatory-2 (OCO-2) was launched to provide global space-based observations of atmospheric $\mathrm{CO}_{2}$ [13]. In the $\mathrm{CO}_{2}$ retrieval algorithm, based on OCO-2 observations, aerosol properties were assumed by simulating data with the forward radiative transfer model and the aerosol information was used to combine different subtypes from the referred average aerosol types [14]. For OCO-2, aerosol optical properties are selected from two dominant and scaled to match from five aerosol types, e.g., dust, smoke, sea salt, sulfate aerosol, organic carbon, and black carbon, in the Modern Era Retrospective-Analysis for Research and Applications model [13].

In contrast, GOSAT has the TANSO-CAI instrument to obtain data on clouds and aerosols, which has a unique UV wavelength band at $0.38 \mu \mathrm{m}$. Despite these advantages, the aerosol properties from TANSO-CAI have not been used for the $\mathrm{CO}_{2}$ gas amounts retrieval from TANSO-FTS because of several limitations (e.g., the derivation of accurate surface reflectance, cloud masking, irregular radiometric 
degradation, different swath and spatial resolution between bands 1, 2, 3 and 4) in retrieving aerosol properties operationally from TANSO-CAI measurements.

In general, accurate surface reflectance is an essential element in the aerosol retrieval process from satellite observations $[6,15,16]$. However, GOSAT observes the entire globe over a three-day period, which makes it difficult to retrieve accurate surface reflectance data because of discontinuous observations. Several studies have attempted to overcome this limitation by calculating surface reflectance, but these still have limited operational use $[10,12,17,18]$. Among these studies, Fukuda et al. [17] retrieved aerosol product from the UV wavelength at $0.38 \mu \mathrm{m}$ with a new surface reflectance correction technique using TANSO-CAI measurements instead of the minimum reflectance method. Aerosol optical depths (AODs) retrieved by applying the new surface reflectance correction technique yielded improved results compared to the minimum reflectance method, but their point by point comparison still showed large deviations. Japan Aerospace Exploration Agency's GOSAT project team is also developing an aerosol algorithm using multi-wavelength and multi-pixel information from TANSO-CAI measurements [19]. Currently, aerosol properties for the $\mathrm{CO}_{2}$ retrieval algorithm utilize aerosol products from the Spectral Radiation-Transport Model for Aerosol Species (SPRINTARS), instead of TANSO-CAI observations [20,21]. Because the observations of $\mathrm{CO}_{2}$ and $\mathrm{CH}_{4}$ from TANSO-FTS measurements have been provided only for clear sky conditions, the final product's coverages are only $7 \%$ of the average output of the total measurement scenes [20].

In addition, TANSO-FTS and CAI have suffered from continuous radiometric degradation at each band. In particular, during the first two years after launch [22,23], the TANSO-CAI spectra at bands 1 and 4 showed degradation of approximately $20 \%$ from the pre-flight test. To date, there has been no study on aerosol retrieval that considers the quantitative radiometric degradation of TANSO-CAI spectra. We adopted annual or seasonal radiometric degradation factors (RDFs) to improve algorithm accuracy, which is expected to improve the accuracy and data coverage of $\mathrm{CO}_{2}$ retrievals from TANSO-FTS [24].

To provide improved aerosol properties, this study developed a TANSO-CAI aerosol algorithm with a spatial resolution of $0.1^{\circ}$ (approximately $10 \mathrm{~km}$ ) over Northeast Asia. Although TANSO-CAI products have spatial resolutions of $0.5 \mathrm{~km}$ (bands 1, 2 and 3) and $1.5 \mathrm{~km}$ (band 4), the algorithm provides coarse resolution results $\left(0.1^{\circ} \times 0.1^{\circ}\right)$ to maintain signal quality and provide accurate aerosol products. To construct LUTs at $0.674 \mu \mathrm{m}$ (band 2) and $0.870 \mu \mathrm{m}$ (band 3), aerosol properties and types were compiled using extensive inversion products from Aerosol Robotic Network (AERONET) sun-photometer observations over Northeast Asia $\left(100^{\circ}-160^{\circ} \mathrm{E}, 10^{\circ}-60^{\circ} \mathrm{N}\right)$. In this study, surface reflectance was determined from 23 path composites of Rayleigh- and gas-corrected reflectance to avoid errors caused by stripe noises. To distinguish aerosol absorptivity and select the aerosol model from the LUTs, a reflectance difference test between UV (band 1) and VIS (band 2) wavelengths, depending on AODs, was used. To remove the cloud contamination in aerosol retrievals, we adopted a concept that combined the normalized difference vegetation index (NDVI) and reflectance ratio at band $2(0.674 \mu \mathrm{m})$ and band $3(0.870 \mu \mathrm{m})$ for cloud mask. To mask turbid waters over ocean, a threshold value for the estimated surface reflectance at band 2 was also introduced.

The TANSO-CAI aerosol algorithm provided aerosol properties such as AOD, size information, and aerosol types from June 2009 to December 2013. In order to evaluate the retrieved AODs from TANSO-CAI measurements, we compared the results with AERONET sun-photometer observations and Aqua/MODerate resolution Imaging Sensor (MODIS) collection 6 (C6) Level 2 observations for the entire period. In the comparisons with AERONET, AOD values were time-averaged within \pm 15 min of TANSO-CAI overpass in and by a $3 \times 3$ pixel grid around the AERONET site. The collocation with MODIS was also done by time difference within \pm 15 min of TANSO-CAI overpass and by spatial grids of $3 \times 3$ pixels over ocean. Furthermore, the retrieved AODs with seasonal and annual RDFs were compared to confirm the impact on accuracy of different RDF temporal resolutions in 2009.

Many $\mathrm{CO}_{2}$ retrieval algorithms have been limited to using inputs of aerosol information from simultaneous aerosol measurements on board the same platform. If more accurate aerosol properties 
were provided for the $\mathrm{CO}_{2}$ retrieval algorithm, these could increase the data coverage of $\mathrm{CO}_{2}$ retrieval and reduce errors induced by aerosol. Using more accurate aerosol properties from TANSO-CAI with the same geometry of TANSO-FTS can improve the accuracy and data coverage of the $\mathrm{CO}_{2}$ retrieval algorithm using TANSO-FTS measurements [25].

In Section 2, the construction of LUTs and the TANSO-CAI aerosol algorithm are described. The results of the TANSO-CAI aerosol algorithm and comparisons with other aerosol products are presented in Section 3. The summary and discussion of the results are presented in Section 4.

\section{Aerosol Models and LUT over Northeast Asia}

\subsection{Aerosol Models}

Accurate aerosol properties such as spectral refractive indices, size distribution, and volume peak ratio (VPR, c2/c1) are essential for the construction of LUTs using a radiative transfer model (RTM) where the VPR is defined as the ratio between fine peak (c1) and coarse peak (c2) value of aerosol size distribution $[4,26]$. As many studies have adopted AERONET data to represent aerosol models [2,5,6,27], and long-term AERONET Level 2 inversion data are used to derive aerosol models over Northeast Asia for this study. Following a method by Kim et al. [4] to distinguish aerosol types using aerosol size information, and assuming bimodal lognormal size distribution and absorption characteristics, AERONET data were classified into twelve types based on fine-mode fraction (FMF) and VPR (Table 2). To distinguish between the size distributions of fine and coarse aerosol over Northeast Asia $\left(10^{\circ}-60^{\circ} \mathrm{N}, 100^{\circ}-160^{\circ} \mathrm{E}\right), \mathrm{FMF}$ values were selected as suggested by Lee et al. [2] (fine aerosol: FMF $>0.6$, coarse aerosol: FMF $\leq 0.6$ ). To distinguish between the absorptivity of absorbing and non-absorbing aerosols, the threshold value in single scattering albedo (SSA) was used as suggested by Remer et al. [6] (absorbing aerosol: SSA $\leq 0.95$, non-absorbing aerosol: SSA $>0.95$ ).

Table 2. Aerosol models were classified using FMF, volume peak ratio, and refractive index at $0.55 \mu \mathrm{m}$ of the AERONET inversion data for the lookup table of the TANSO-CAI aerosol algorithm.

\begin{tabular}{cccc}
\hline Aerosol Model (SSA, FMF) & VPR $(\mathbf{c} \mathbf{2} \mathbf{c} \mathbf{1})$ & RI_Real @ 0.55 $\boldsymbol{\mu m}$ & RI_Imaginary @ 0.55 $\boldsymbol{\mu m}$ \\
\hline AA1 $(\leq 0.95,>0.6)$ & 0.5 & 1.440 & 0.018 \\
AA2 $(\leq 0.95,>0.6)$ & 0.9 & 1.440 & 0.018 \\
AA3 $(\leq 0.95,<0.4)$ & 2.0 & 1.550 & 0.0028 \\
AA4 $(\leq 0.95,<0.4)$ & 4.0 & 1.550 & 0.0028 \\
AA5 $(\leq 0.95,<0.4)$ & 10.0 & 1.550 & 0.0028 \\
AA6 $(\leq 0.95,<0.4)$ & 30.0 & 1.550 & 0.0028 \\
NA1 $(>0.95,>0.6)$ & 0.3 & 1.423 & 0.0043 \\
NA2 $(>0.95,>0.6)$ & 0.5 & 1.423 & 0.0043 \\
NA3 $0.4 \leq$ FMF $\leq 0.6)$ & 2.0 & 1.445 & 0.0053 \\
NA4 $(0.4 \leq$ FMF $\leq 0.6)$ & 4.0 & 1.445 & 0.0053 \\
NA5 $(0.4 \leq$ FMF $\leq 0.6)$ & 10.0 & 1.445 & 0.0053 \\
NA6 $(0.4 \leq$ FMF $\leq 0.6)$ & 30.0 & 1.445 & 0.0053 \\
\hline
\end{tabular}

\subsection{Construction of LUT}

An algorithm based on the LUT approach [5,6,28-31] was developed to retrieve aerosol optical properties over Northeast Asia with TANSO-CAI measurements. Because the wavelength combination of TANSO-CAI at bands 2 and 3 determines aerosol amounts and their size information, the TANSO-CAI aerosol algorithm was developed to retrieve aerosol optical properties using two wavelengths $(0.674$ and $0.870 \mu \mathrm{m})$ [2-4,28]. A radiative transfer code, Rstar6b [30,32] was used to construct LUTs for each aerosol model, where the TOA reflectance was calculated for combinations of eight solar zenith angles $\left(0^{\circ}, 10^{\circ}, 20^{\circ}, 30^{\circ}, 40^{\circ}, 50^{\circ}, 60^{\circ}, 70^{\circ}\right)$, eight satellite zenith angles $\left(0^{\circ}, 10^{\circ}\right.$, $\left.20^{\circ}, 30^{\circ}, 40^{\circ}, 50^{\circ}, 60^{\circ}, 70^{\circ}\right)$, ten relative azimuth angles $\left(0^{\circ}, 20^{\circ}, 40^{\circ}, 60^{\circ}, 80^{\circ}, 100^{\circ}, 120^{\circ}, 140^{\circ}, 160^{\circ}\right.$, $\left.180^{\circ}\right)$, four surface reflectances $(0.0,0.1,0.2,0.3)$, and eight AODs (0.0, 0.25, 0.5, 1.0, 1.5, 2.0, 2.5, 
3.0) for each aerosol type at 0.674 and $0.870 \mu \mathrm{m}[17,30,32]$. The observed reflectances at the two wavelengths of TANSO-CAI were then compared with top-of-the-atmosphere (TOA) reflectance from precalculated LUTs.

\subsection{Reflectance Correction with Radiometric Degradation Radiances}

Radiances of GOSAT Level 1B (L1B), which were converted by adopting prelaunch calibration factors, were used to retrieve AODs. However, Kuze et al. [33,34] estimated the RDFs of GOSAT sensors and proposed annual results by the vicarious calibration campaigns (VCC), which showed the particularly strong initial degradation of TANSO-CAI spectra in the first two years. According to Kuze et al. [34], initial degradation was estimated at $-17 \%$ and $-18 \%$ for bands 1 and 4 , respectively, with root mean square error (RMSE) of $6 \%$. For this reason, the L1B radiances were corrected with RDFs to improve the accuracy of the TANSO-CAI aerosol algorithm, and then utilized to retrieve surface reflectance and aerosol properties. JAXA's GOSAT project team provided the monthly results of radiometric cross-calibrations of TANSO-CAI at bands 2, 3 and 4 with MODIS L1B products aboard the Aqua satellite in June and October 2009, and March 2010 as well as the annual RDFs that were recalculated using Pstar3 vector RTM [35] by Kuze et al. [34]. Table 3 lists the RDFs used for the correction of TANSO-CAI L1B radiances.

This study used seasonal and annual RDFs from June 2009 to March 2010 and from April 2010 to December 2013, respectively.

Table 3. Used radiometric degradation factors (RDFs) for TANSO-CAI and JAXA's correction with MODIS measurements; where $a$ and $b$ are the values of slope and offset for the correction of each band, respectively. (2009.092-2010.090: applied JAXA correction from JAXA GOSAT project team (JAXA, 2015); 2010.091-2013.365: applied annual RDFs, which is recalculated from Kuze et al. [34], by Kuze).

\begin{tabular}{ccccccccc}
\hline \multirow{2}{*}{ Year/Julian Day } & \multicolumn{2}{c}{ Band 1 } & \multicolumn{2}{c}{ Band 2 } & \multicolumn{2}{c}{ Band 3 } & \multicolumn{2}{c}{ Band 4 } \\
\cline { 2 - 9 } & $\mathbf{a}$ & $\mathbf{b}$ & $\mathbf{a}$ & $\mathbf{b}$ & $\mathbf{a}$ & $\mathbf{b}$ & $\mathbf{a}$ & $\mathbf{b}$ \\
\hline $2009 / 092-273$ & 1.163 & 0.0 & 0.956 & -1.305 & 1.006 & -0.232 & 1.117 & -0.432 \\
$2009 / 274-365$ & 1.180 & 0.0 & 0.978 & -0.334 & 1.034 & -0.331 & 1.078 & 1.251 \\
$2010 / 001-090$ & 1.201 & 0.0 & 0.967 & 1.203 & 1.021 & 0.930 & 1.111 & -0.056 \\
$2010 / 091-365$ & 1.201 & 0.0 & 1.061 & 0.0 & 1.063 & 0.0 & 1.172 & 0.0 \\
$2011 / 001-365$ & 1.202 & 0.0 & 1.018 & 0.0 & 1.021 & 0.0 & 1.118 & 0.0 \\
$2012 / 001-366$ & 1.228 & 0.0 & 1.063 & 0.0 & 1.045 & 0.0 & 1.130 & 0.0 \\
$2013 / 001-365$ & 1.150 & 0.0 & 0.996 & 0.0 & 1.000 & 0.0 & 1.170 & 0.0 \\
\hline
\end{tabular}

\subsection{Description of Data Mask}

To improve the accuracy of the final results from the TANSO-CAI aerosol algorithm, a number of masking methods were considered, such as the satellite zenith angle test for the elimination of smoothing path edges, thick cloud, turbid water, ocean glint effect, etc. Table 4 lists the parameters for testing the lower and upper threshold limits, standard deviation tests, and other masking values used in the current TANSO-CAI aerosol algorithm. 
Table 4. Mask of reflectance smoothing edges, cloud, turbid, and glint angle.

\begin{tabular}{ccccc}
\hline Mask & Threshold Test & $\begin{array}{c}\text { Lower } \\
\text { Limit }\end{array}$ & $\begin{array}{c}\text { Upper } \\
\text { Limit }\end{array}$ & Surface Type \\
\hline Reflectance smoothing edges & Satellite zenith angle & 0 & $42.5^{\circ}$ & Ocean/Land \\
\hline & $\mathrm{R} 1$ & 0 & 0.35 & Ocean/Land \\
& R2, R3, R4 & 0 & 0.30 & Ocean/Land \\
Cloud & Standard Deviation at R1, R2, R3, R4 & 0 & 0.0025 & $\begin{array}{c}\text { Ocean/Land } \\
\end{array}$ \\
& Surface reflectance @ band 4 & 0 & 0.25 & Ocean/Land \\
& NDVI \& R(2)/R(3) & NDVI $>-0.25$ & Ocean (option) \\
\hline Turbid water & Surface reflectance @ band 2 & 0 & 0.101 & Ocean \\
\hline Glint angle & Glint angle & 0 & $23.0^{\circ}$ & Ocean \\
\hline
\end{tabular}

\subsubsection{Mask of Swath Edge}

One characteristic of GOSAT-CAI L1B data from the GOSAT user interface gateway [36] is that the edge radiances of each path were smoothed at bands 1,2 and 3 [36,37]. To eliminate the impact of the edge data, the TANSO-CAI aerosol algorithm adopted L1B pixels within $42.5^{\circ}$ of satellite zenith angles.

\subsubsection{Mask of Cloud}

To provide cloud and aerosol information simultaneously with TANSO-FTS measurements, TANSO-CAI is designed to observe clouds and aerosols [10,12]. However, the detection of thin clouds over bright surfaces is constrained by the lack of thermal infrared (IR) channels, which results in contaminations in the retrieved aerosol properties. Since the accuracy of the aerosol information of TANSO-CAI is not guaranteed, it is not currently utilized for the $\mathrm{CO}_{2}$ retrieval algorithm using TANSO-FTS measurements [12].

However, we are trying to improve the aerosol retrieval algorithm by introducing more appropriate cloud masking methods in this study. To mask bright pixels such as clouds and snow, the TANSO-CAI aerosol algorithm first adopted basic approaches such as threshold tests and standard deviation tests with $3 \times 3$ pixels at each band (Table 4) [6,38]. Owing to the lack of thermal IR channels in the TANSO-CAI, we have introduced a method that combines the NDVI and ratio of two bands over ocean for cloud masking. In general, the NDVI is calculated in the individual near-IR (NIR) and VIS wavelengths of satellite observations to identify vegetated areas, which are more sensitive to incoming photosynthetically active radiation compared to relatively dark surfaces over land [39-41]. Although NDVI is mainly used to identify vegetated areas, it is also useful for cloud masking. Ishida et al. [12] presented an effective method to remove clouds using the NDVI and reflectance ratio in bands 2 and 3 (R(band 2)/R(band 3)) over water and land, respectively. The NDVI value for the TANSO-CAI algorithm is defined as

$$
\mathrm{NDVI}=\frac{\mathrm{R}(\text { band } 3)-\mathrm{R}(\text { band } 2)}{\mathrm{R}(\text { band } 3)+\mathrm{R}(\text { band } 2)}
$$

where $R$ is the reflectance corrected with RDFs.

Ishida et al. [12] proposed the thresholds to mask cloud over ocean. However, large errors remain when using only NDVI over ocean. Hence, we adopted the reflectance ratio at 0.674 and $0.870 \mu \mathrm{m}$ (R(band 2)/R(band 3)) with the NDVI to detect thin clouds and cloud edges over ocean. In other words, this new concept of combining the NDVI and R(band 2)/R(band 3) was introduced to compensate for the lack of a thermal IR band in the TANSO-CAI aerosol algorithm. Through many tests and retrievals, we confirmed that the method using the NDVI and R(band 2)/R(band 3) is useful in eliminating cloud edges and thin clouds. However, we also found that it was not sensitive enough to distinguish between heavy dusts and clouds over ocean. Furthermore, it cannot be applied over land because the NDVI is affected by the condition of the surface covered by vegetation. Thus, it is used only for 
ocean observations because the surface reflectance over ocean is relatively constant compared to that over land.

Figure 1 shows an example of cloud masking using the combined NDVI and R(band 2)/R(band 3) over ocean. Figure 1a shows a false color image derived from TANSO-CAI over Northeast Asia on 24 December 2009. Figure 1b,c show the distributions of calculated NDVI and R(band 2)/R(band $3)$, respectively. Over ocean, thin clouds and cloud edge regions matched those of the NDVI value $(>-0.25)$ and $R($ band 2$) / R($ band 3$)(\leq 1.5)$. As shown in Figure $1 d$, after the masking by NDVI and $\mathrm{R}$ (band 2)/R(band 3), thin clouds and cloud edges were clearly eliminated from the reflectance at band 2. In other words, if an estimated pixel for AOD retrieval has NDVI $>-0.25$ and $R($ band 2$) / R$ (band $3) \leq 1.5$, then that pixel should be classified as a cloud pixel. Although this method has difficulty distinguishing between heavy dust and clouds over ocean, this combined concept is very effective in removing thin clouds and cloud edges over ocean. On the other hand, if the scene has the heavy dust aerosol over ocean, the corresponding pixel can be classified as cloudy.

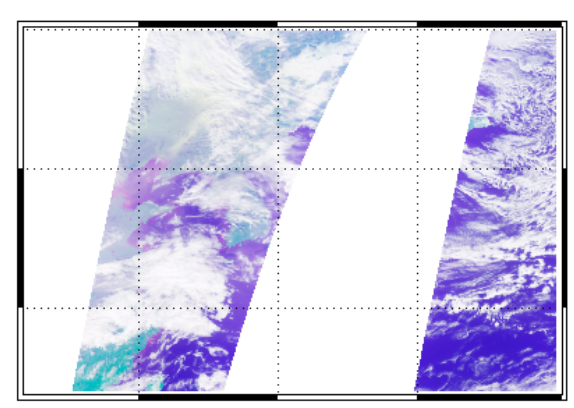

(a)

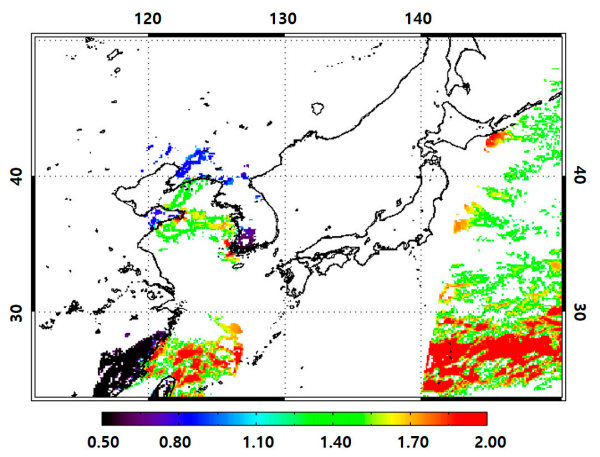

(c)

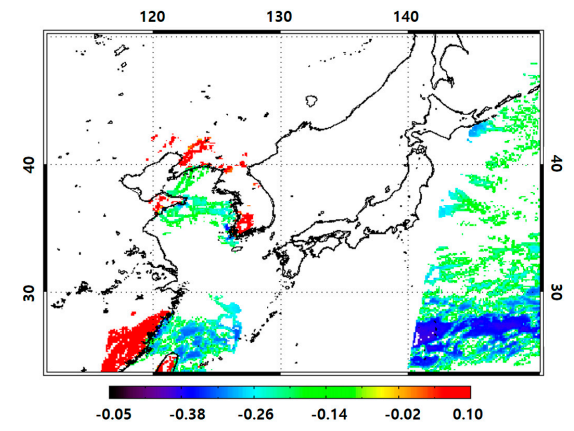

(b)

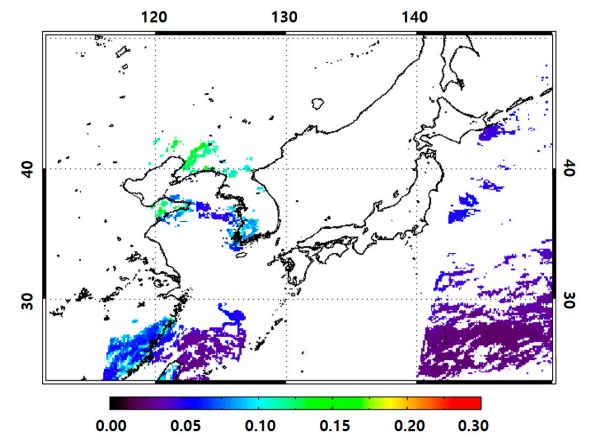

(d)

Figure 1. An example of the (a) TANSO-CAI false color image; (b) NDVI; (c) ratio of band 2/band 3 , and (d) reflectance after cloud mask using NDVI and reflectance ratio at bands 2 and 3 from TANSO-CAI with $0.1^{\circ}$ grid pixel resolution on 24 December 2009. The white area represents that lack of observation swath of TANSO-CAI and masked region by cloud masking method in the TANSO-CAI aerosol algorithm.

\subsubsection{Mask of Turbid Water}

Surface reflectance over ocean typically has values of less than 0.10 at visible regions. However, surface reflectance over turbid water regions shows high values similar to that over land. The retrieval of AODs over turbid water regions tends to have large errors due to inaccurate values of surface reflectance [2]. To reduce errors and discontinuity in AOD retrieval over turbid water, many studies have adopted various methods to either eliminate turbid water regions over ocean $[5,6]$ or retrieve AOD using NIR channel [42].

For this reason, we did not retrieve AODs over turbid water regions when the value of surface reflectance was greater than 0.10 at band 2 over ocean (Figure 2). The threshold of 0.10 was determined 
after finding the maximum value of the ocean's surface reflectance over Northeast Asia for a year from TANSO-CAI measurements. Figure 2a,b show a true color image derived from Aqua/MODIS and a map of reflectance, respectively, after masking turbid water regions over ocean using TANSO-CAI Level 1B data on 10 March 2011. With turbid water masking, thin clouds and cloud edges over ocean were also removed, although we applied the method for strictly masking clouds, as shown in Figure 2. We can confirm that using the threshold surface reflectance at band 2 was very simple and effective for turbid water masking.

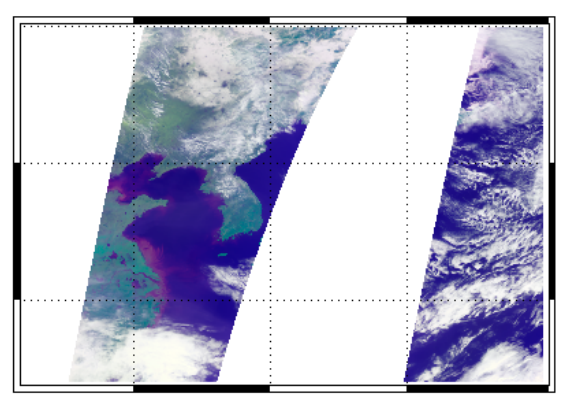

(a)

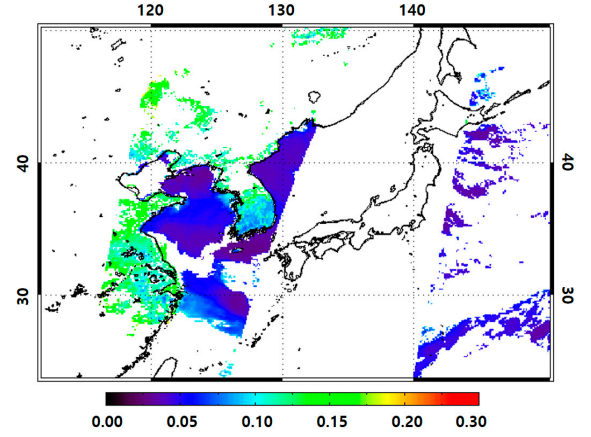

(b)

Figure 2. An example of (a) the TANSO-CAI false color image and (b) the reflectance after masking turbid water regions over Northeast Asia using TANSO-CAI Level 1B data on 10 March 2011.

\subsubsection{Mask of Sun Glint over Ocean}

At the sun glint region over ocean, the aerosol optical properties were not retrieved to avoid the errors obtained in many satellite studies [5,6,31]. This masking method was also chosen to reduce errors due to glint contamination over ocean.

The glint angle is usually defined as

$$
\theta_{\text {glint }}=\cos ^{-1}\left[\left(\cos \theta_{s} \cos \theta_{v}\right)+\left(\sin \theta_{s} \sin \theta_{v} \cos \phi\right)\right]
$$

where $\theta_{s}, \theta_{v}$, and $\phi$ are the solar zenith angle, satellite zenith angle, and relative azimuth angle between the sun and satellite, respectively [5,6]. Aerosol retrievals from satellite have been limited to solar zenith angles smaller than $70^{\circ}$ to avoid errors in the plane-parallel atmosphere [38]. When the glint angle of TANSO-CAI calculated by Equation (2) is greater than $23^{\circ}$, glint contamination can be avoided in AOD retrieval. In the TANSO-CAI aerosol algorithm, the pixel was masked with both solar zenith angle smaller than $70^{\circ}$ and the glint angle smaller than $23^{\circ}$ (Figure $3 \mathrm{~b}, \mathrm{c}$ ).

\subsection{TANSO-CAI Retrieval Grid Boxes}

For the calculation of surface reflectance from satellite measurements, it is important to identify contaminated pixels one-by-one and then keep clear pixels only. Remer et al. [6,43] suggested the retrieval boxes to ensure the accuracy of the reflectance, and aerosol properties were retrieved from the box of $20 \times 20$ pixels $(10 \times 10 \mathrm{~km}$ resolution). The 400 pixels in the box contained the pixel of clear sky, cloud, water, snow, or ice. Before the retrieval of aerosol properties and surface reflectance, it is necessary to evaluate each pixel to identify whether the pixel is contaminated by cloud, water, snow, or ice. The pixel remaining after masking and dark target selection is still possibly contaminated by cloud shadows or odd surface at the dark end or residual cloud contamination and odd surface at the bright end. So after cloud masking [38], the darkest and brightest $25 \%$ of remaining pixels in the retrieval box $(20 \times 20$ pixels) in the MODIS aerosol algorithm were discarded over ocean, and the darkest $20 \%$ and brightest $50 \%$ of remaining pixels were discarded over land [6]. Thus, number of pixels after cloud 
masking and deselecting the brightest and darkest pixels from the box of $20 \times 20$ pixels $(0.5 \times 0.5 \mathrm{~km}$ resolution) must be remained at least $10 \%$ [44].

Similarly, as in MODIS aerosol algorithm, the retrieval boxes and selection procedure of $20 \times$ 20 pixels were adopted in the TANSO-CAI aerosol algorithm to reduce errors caused by bad reflectance data. After sediment masking by the darkest and brightest pixels, each retrieval box was averaged for aerosol retrievals in the TANSO-CAI aerosol algorithm only when the remaining pixels were over 44 pixels $(\geq 10 \%)$. As the channel 4-7 (VIS) of MODIS, TANSO-CAI has the same spatial resolution (500 m) at bands 1, 2 and 3, thus adopted these threshold values for its aerosol algorithm to remove possible contaminated signal by cloud or cloud shadows and odd surface at the bright and dark ends.

\subsection{Surface Reflectance Retrieval}

After masking the pixels with clouds and sediments, the averaged pixels were gridded in $0.1^{\circ}$ resolution for the retrieval of the surface reflectance and AODs in the TANSO-CAI algorithm. To calculate the surface reflectance from TANSO-CAI L1B measurements, the minimum reflectance composite method was used, as suggested by Kaufman et al. [15].

To improve the accuracy of aerosol retrievals from satellite observations, the accurate surface reflectance is an essential element. However, the three-day revisit schedule of the GOSAT makes it difficult to calculate the accurate surface reflectance using TANSO-CAI measurements. Moreover, according to JAXA [45], stripe patterns appear in the TANSO-CAI L1B data. To avoid the stripe patterns in the surface reflectance, we used a search window for the same 23 paths before and after a target day instead of the previous 30-day search window [46]. The selection of the same paths can reduce the errors due to stripes, where the window width (retrieval day \pm 11 -paths) was selected by testing the probability of finding a clear sky pixel through various search window tests. The minimum composite was also applied to all four channels. Here, the band $2(0.674 \mu \mathrm{m})$ was used as a reference channel of each pixel when the day of minimum value is different at each pixel. After surface reflectance retrievals, another threshold test was applied with surface reflectance calculated in the NIR wavelength. In other words, if the retrieved surface reflectance at band 4 is greater than 0.25 , the pixel is discarded to remove the remaining errors in surface reflectance caused by bright signals. Despite these efforts, there were still difficulties in selecting surface reflectance from the long search window of TANSO-CAI L1B v01.00, which is the version that has large discontinuities in observations due to dark noise [45].

\subsection{Reflectance Difference Test to Select Aerosol Type from LUTs}

The Aerosol Index (AI) has been widely used to distinguish aerosol types from the two UV channels of satellite aerosol observations in GOME and OMI [47-51]. Because the TANSO-CAI sensor has only one UV channel, it is difficult to apply the AI method to distinguish aerosol absorptivity in the TANSO-CAI aerosol algorithm. A separate, coordinated study was conducted to retrieve AI from a single UV channel [52].

To determine the aerosol type, i.e., absorbing aerosol (AA) or non-absorbing aerosol (NA), the reflectance difference method instead of the AI method was used the slope between UV and VIS wavelengths was considered. When AA exists in the atmosphere, the radiative absorptivity signal appears significantly larger in the UV than in the VIS wavelength. In contrast, when NA exists in the atmosphere, the radiative absorptivity signal is relatively smaller in the UV than in the VIS wavelength. Because of the radiation characteristics of aerosol absorptivity, the slope between the UV and VIS spectra shows contrast in direction, depending on the aerosol type [50]. This method is based on a concept for which the differences in aerosol absorbance between the UV (band 1: $0.380 \mu \mathrm{m}$ ) and VIS (band 2: $0.674 \mu \mathrm{m}$ ) wavelengths appear more clearly. Figure 3a presents an example of the reflectance difference of each aerosol type from LUTs at four individual bands, depending on aerosol loading $(\mathrm{AOD}=1)$ and clear condition $(\mathrm{AOD}=0)$. Although there is a difference in gradient depending on aerosol loading, the tendency of the slope between bands 1 and 2 by aerosol types is similar to that of Figure $3 a-c$ show maps of the reflectance differences with $0.1^{\circ}$ grid pixel resolution over Northeast 
Asia on 9 April 2011 and 27 April 2012, respectively. Some regions over the Yellow Sea in the Korean peninsula and North Pacific Ocean were eliminated by glint angle masking. As shown in Figure 3b,c, AA type aerosols (absorbing and dust aerosols) have positive values in the difference test between bands 1 and 2, in contrast to NA types (non-absorbing and mixture aerosols) which have negative values. Figure $3 \mathrm{~d}$,e show maps of OMI-AI product with $1^{\circ}$ grid pixel resolution in the case of dust aerosol on 9 April 2011 and 27 April 2012, respectively. Figure 3b,d and Figure 3c,e show consistent results for highly absorbing aerosol areas, especially over China, Korea, and the Bohai Sea.

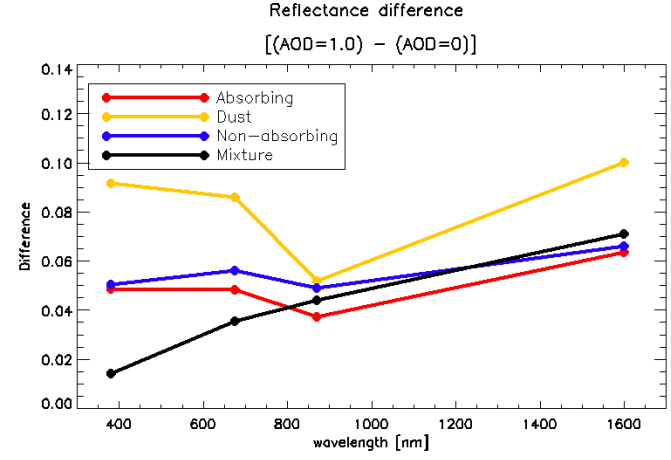

(a)

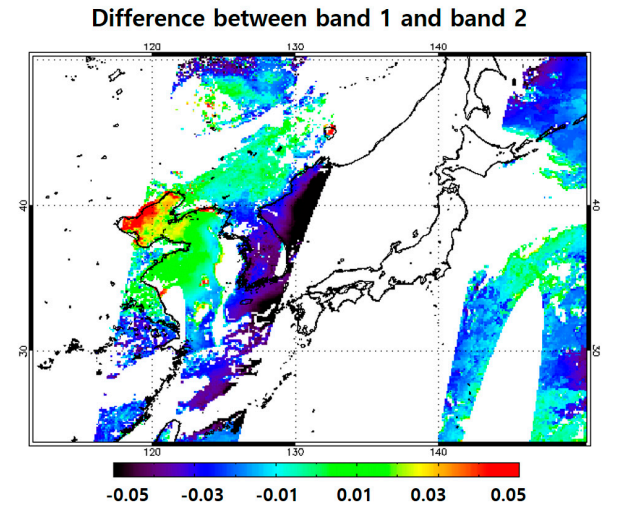

(c)

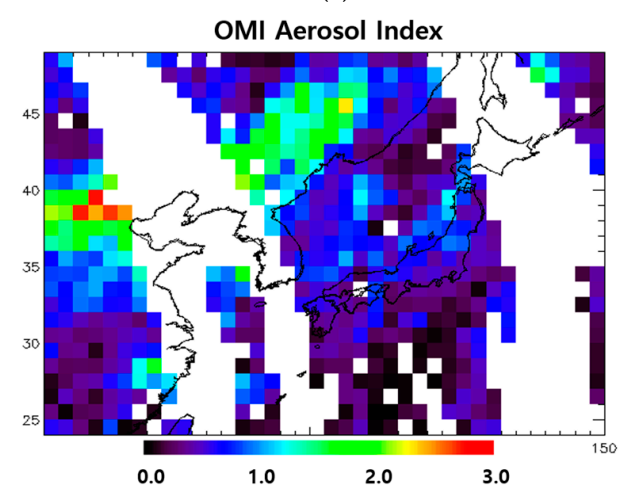

(e)

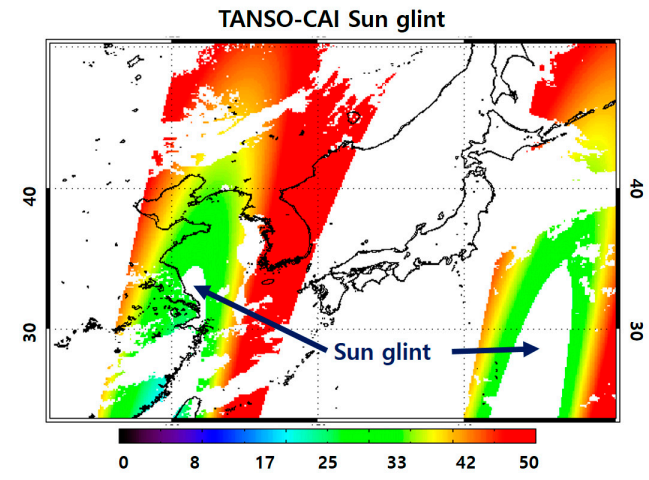

(b)

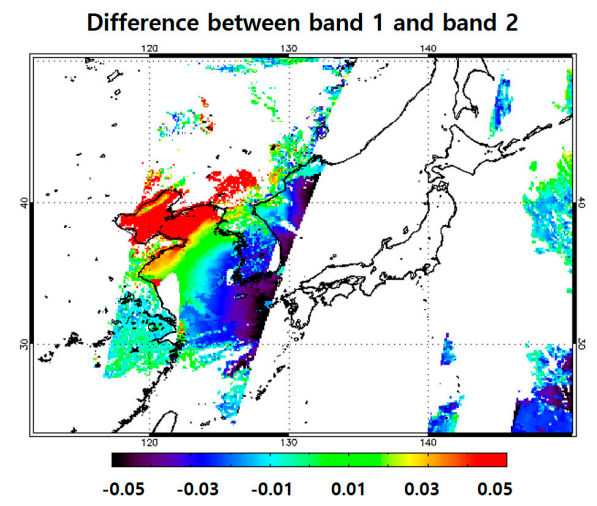

(d)

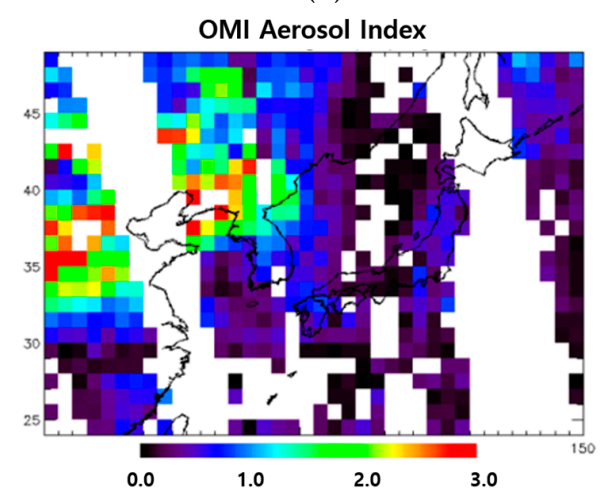

(f)

Figure 3. Examples of (a) the reflectance differences of TANSO-CAI channels depending on AODs; (b) An example of sun glint angle calculated from TANSO-CAI aerosol algorithm on 9 April 2011. The regions where the angle is smaller than $23^{\circ}$ represent sun glint. Examples of the reflectance differences using bands 1 and 2 from TANSO-CAI with $0.1^{\circ}$ grid pixel resolution on (c) 9 April 2011 and (d) 27 April 2012. Images of aerosol index from OMI Level 3 measurements with $1^{\circ}$ grid pixel resolution on (e) 9 April 2011 and (f) 27 April 2012, respectively. 


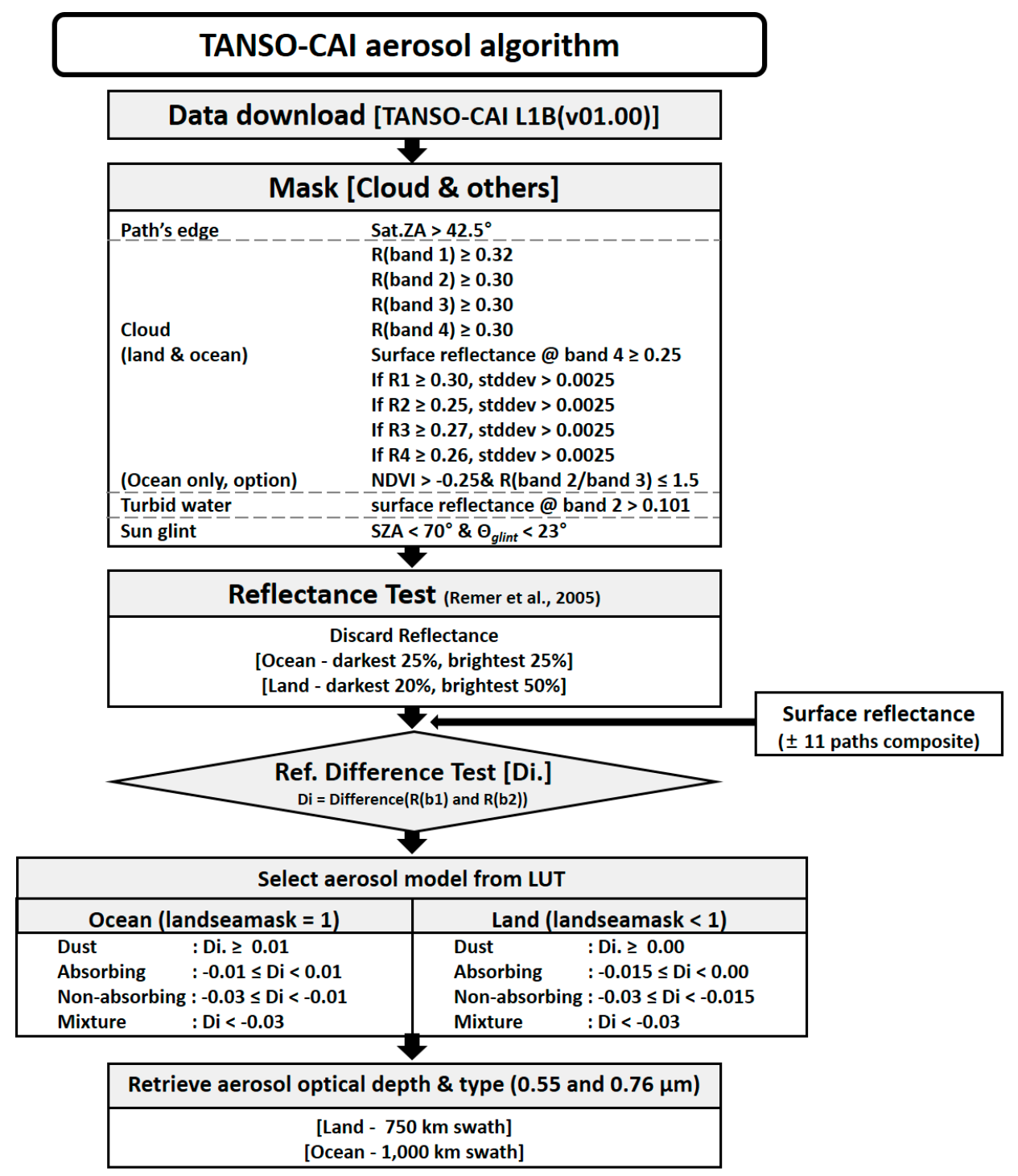

Figure 4. The flowchart of the TANSO-CAI aerosol retrieval algorithm.

We can confirm that the test is very useful to distinguish between AA and NA aerosols for model selection from LUTs. According to our test results of the reflectance differences depending on AODs, it is difficult to distinguish between AA and NA when AOD is smaller than 0.25 (the smallest LUT of eight AOD models in this study). Similar to many studies that have experienced difficulty distinguishing between aerosol types for low AOD [53-55], the TANSO-CAI aerosol algorithm also showed relatively large uncertainty with the low AOD pixel. Currently, the threshold values for aerosol model selection by LUTs are set by reflectance difference test over land and ocean, which requires some fine adjustments with changing RDFs. The detailed flowchart of the TANSO-CAI aerosol algorithm is shown in Figure 4.

\section{Results of TANSO-CAI Aerosol Products}

This study focused on the development of an algorithm to retrieve aerosol properties from GOSAT TANSO-CAI L1B measurements. The optical depths and aerosol types at 0.55 and $0.76 \mu \mathrm{m}$ were retrieved from the TANSO-CAI aerosol algorithm. Considering the different swaths of $1000 \mathrm{~km}$ for bands 1, 2 and 3, and $750 \mathrm{~km}$ for band 4, channels were selected differently: 1-4 over ocean and 1-3 
over land. Thus, aerosol properties were produced over swaths of $750 \mathrm{~km}$ and $1000 \mathrm{~km}$ over land and ocean, respectively.

Retrieved AODs at $0.55 \mu \mathrm{m}$ were compared with those from AERONET and Aqua/MODIS, and aerosol properties at $0.76 \mu \mathrm{m}$ were also provided for $\mathrm{CO}_{2}$ retrievals using TANSO-FTS measurements from June 2009 to December 2013 over Northeast Asia $\left(112^{\circ}-150^{\circ} \mathrm{E}, 24^{\circ}-50^{\circ} \mathrm{N}\right)$. The AODs retrieved from the algorithm and comparisons of aerosol products are described in detail in Sections 3.1 and 3.2, respectively.

\subsection{Results from the Algorithm}

Figure 5 shows examples of the AODs retrieved from the TANSO-CAI aerosol algorithm (CAI-AOD) over Northeast Asia. The left column in Figure 5 shows color images derived from TANSO-CAI L1B data. The middle column shows selected AOD images generated with spatial resolution of $0.3^{\circ}$ latitude $\times 0.3^{\circ}$ longitude using the Deep Blue (DB) or Dark Target (DT) algorithm of Aqua/MODIS C6 Level 2 data. The right column shows CAI-AOD images retrieved with spatial resolution of $0.1^{\circ} \times 0.1^{\circ}$. CAI-AODs had reasonably good agreement with those from MODIS despite limitations such as the difficulty in surface reflectance retrieval owing to the three-day revisit cycle of GOSAT, estimation by RDFs, and cloud masking without IR channels.

Figure 5a shows a case of severe smoke plumes spread over Jining and Xuzhou in China on 3 June 2009. The CAI-AOD values show distinct signals over Jining and Xuzhou and the features are similar with those of MODIS except for some regions over Changchun, China. Figure $5 b$ shows a case of smoke plumes spread over Tianjin, Huludao, Yingkou, and the Bohai Sea of China, and another smoke plume with clouds south of Jeju Island, Korea, on 1 September 2009. The CAI-AODs retrieved after cloud masking were consistent with those from the MODIS DT algorithm. However, CAI-AODs over the Korean peninsula were occasionally not provided owing to the threshold value of 0.25 to reduce the bright surface reflectance at band 4, as shown in Figure 4. Figure 5c shows a case of smoke on a rainy day in Seoul, Korea, with precipitation recorded at $23.5 \mathrm{~mm}$ on 12 September 2009. Despite the overall cloud cover over Korea and Japan, the CAI-AODs were retrieved for some southern parts of Korea, in contrast to the MODIS DT algorithm. However, TANSO-CAI aerosol algorithm still has limitations with regard to retrieval over bright land surface regions. The CAI-AODs retrieved in some parts of northern China and over Ulaan-Uul, Mongolia, showed greater values than the results from MODIS, as shown in Figure 5c. Among them, some regions over the Yellow Sea around the Korean peninsula and Pacific Ocean were eliminated by sun glint masking (see Figure $5 \mathrm{a}-\mathrm{c}$ ). Figure $5 \mathrm{~d}$, $\mathrm{f}$ show cases of a rainy day with precipitation recorded at $13.0 \mathrm{~mm}$ and $2.5 \mathrm{~mm}$ on 13 October 2009 and 16 October 2009, respectively, in Seoul, Korea, with strong smoke plumes spread over Lianyungang, Shanghai, and the Yellow Sea. Aerosol properties were retrieved over the Yellow Sea, but the CAI-AOD values were also greater compared to those from the MODIS DT algorithm, which may be attributed to the remaining cloud contamination. In case of MODIS DT algorithm, some AOD values over ocean were not retrieved by sun glint masking on the same day. Figure 5e represents the case of a foggy day with smoke belts spread over the Yellow Sea and East Sea on 15 October 2009. While CAI-AODs over the Yellow Sea were not retrieved owing to the coverage of the GOSAT, the smoke belt over the East Sea was retrieved clearly from TANSO-CAI aerosol algorithm. The CAI-AOD values were consistent with those from the MODIS DT. Furthermore, the results from the TANSO-CAI aerosol algorithm were at least comparable with, and sometimes better than those from the MODIS DT algorithm. Figure $5 \mathrm{~g}$ shows the case of a clear day in the Korean peninsula on 18 October 2009. The CAI-AODs in most regions represent low values over land around the Korean peninsula and Kyushu Island, Japan. However, CAI-AODs retrieved over ocean showed more sensitive than those from the MODIS DT. Figure $5 \mathrm{~h}$ shows that case of smoke spreading across the Yellow Sea to Jeju Island on 21 October 2009. Although the TANSO-CAI swath did not cover the area stretching from the Yellow Sea to Japan, high CAI-AODs were identified over the same areas. The cases in Figure 5 demonstrate that aerosol plumes occurred frequently from East China to the Yellow Sea, and were captured very well by the TANSO-CAI aerosol algorithm. 

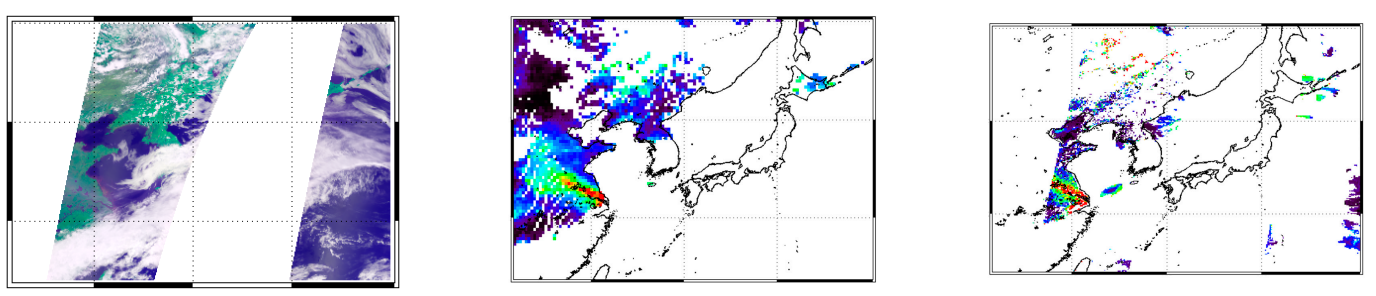

(a) 3 June 2009
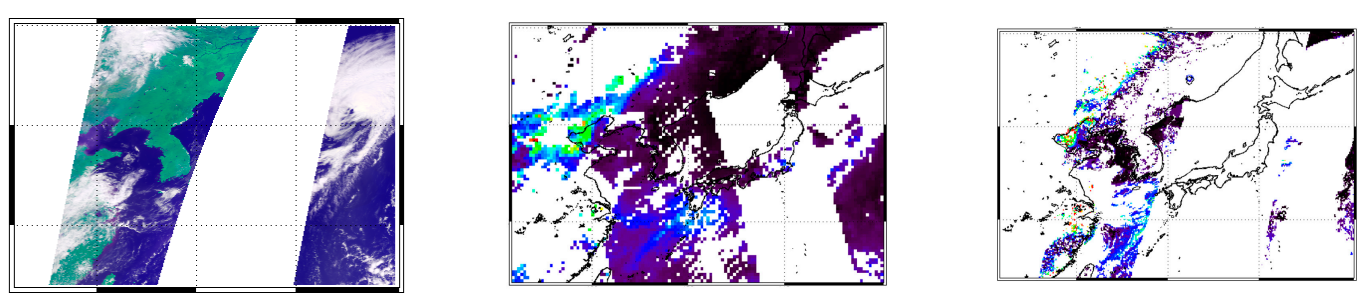

(b) 1 September 2009
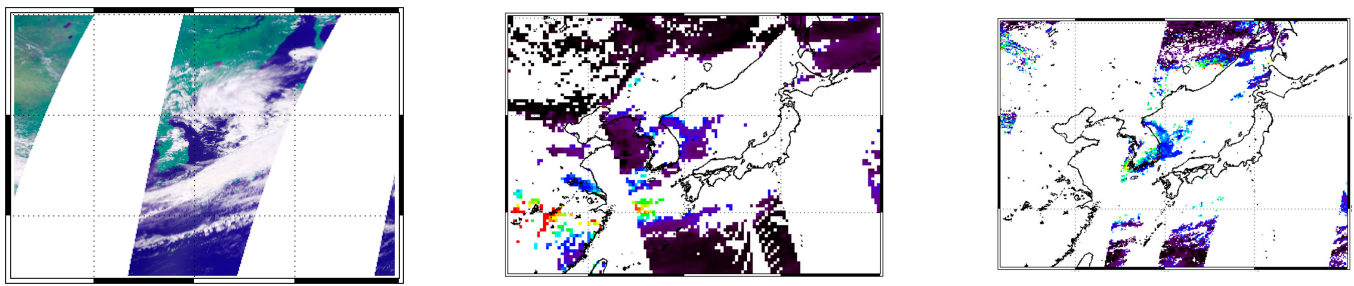

(c) 12 September 2009
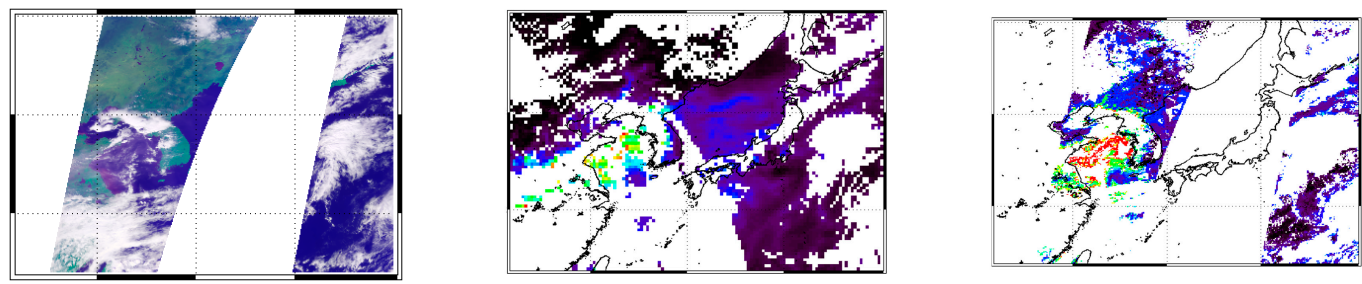

(d) 13 October 2009
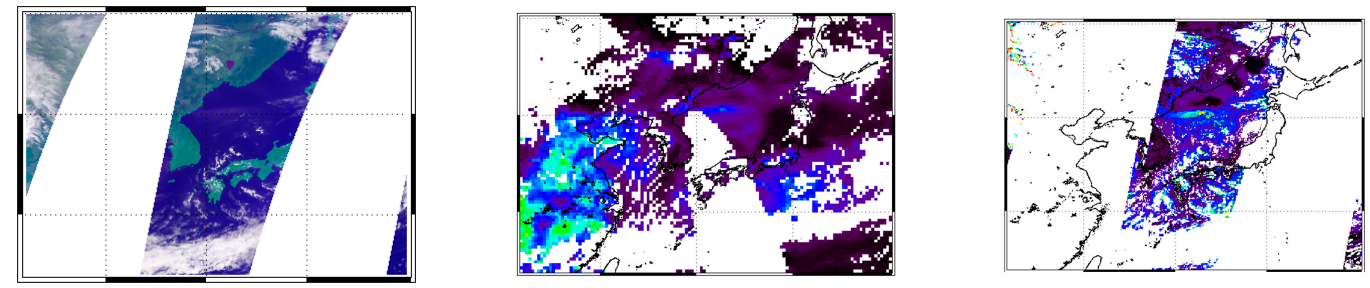

(e) 15 October 2009
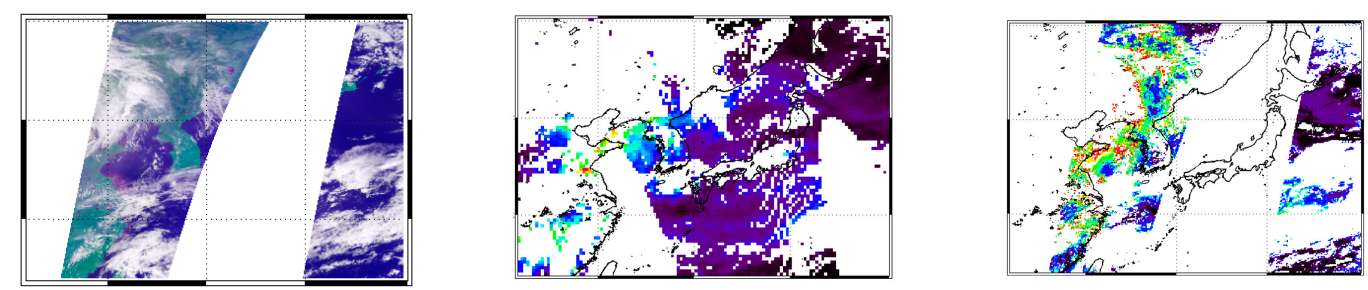

(f) 16 October 2009

Figure 5. Cont. 

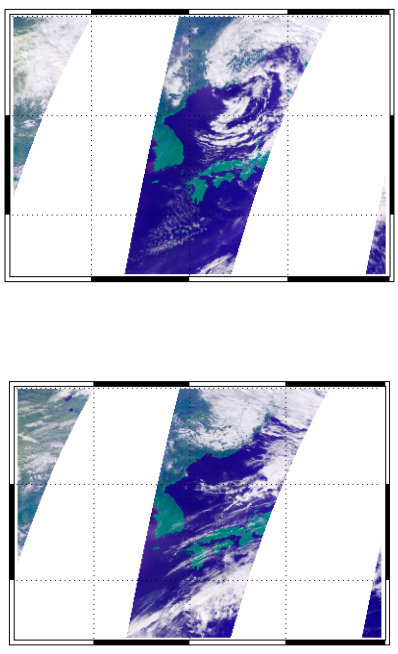
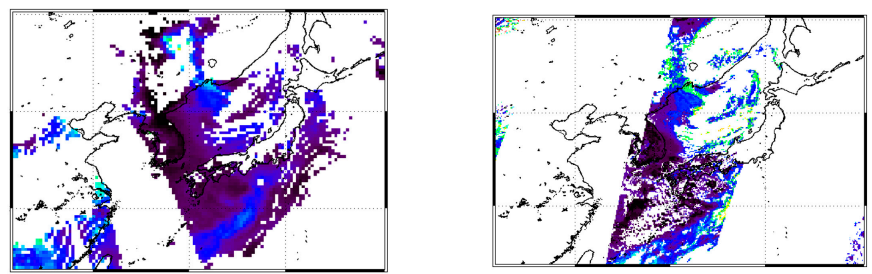

(g) 18 October 2009

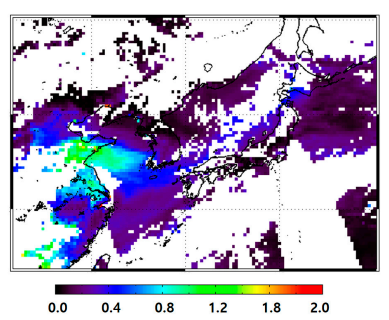

(h) 21 October 2009

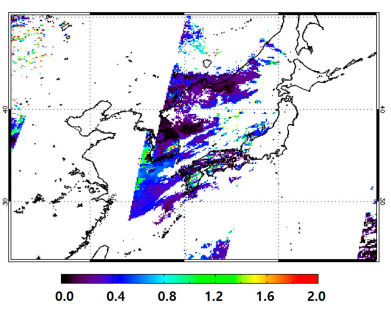

Figure 5. Examples of the (left) TANSO-CAI false color image, (middle) Aqua/MODIS DB_AOD or DT_AOD (collection 6) with $0.3^{\circ}$ grid pixel resolution, and (right) CAI AOD with $0.1^{\circ}$ grid pixel resolution over Northeast Asia on (a) 3 June; (b) 1 September; (c) 12 September; (d) 13 October 2009; (e) 15 October; (f) 16 October; (g) 18 October; and (h) 21 October 2009. Black color represents 0.0 of AOD and red color means 2.0 of AOD.

\subsection{Comparison of Aerosol Products}

To evaluate the retrieval accuracy of the TANSO-CAI aerosol algorithm, the CAI-AODs at $0.55 \mu \mathrm{m}$ were compared with results from AERONET sun-photometers and Aqua/MODIS C6 Level 2 measurements in Sections 3.2.1 and 3.2.2, respectively, from June 2009 to December 2013 over Northeast Asia. MODIS aerosol products of Aqua (MYD04_L2) at $10 \mathrm{~km}$ resolution [56], were selected because the datasets were close to the overpass time of GOSAT and their qualities were better than those of Terra.

For the comparison between TANSO-CAI and AERONET, two datasets were collocated and averaged within \pm 15 min of $3 \times 3$ pixels ( $0.3^{\circ}$ latitude $\times 0.3^{\circ}$ longitude) of CAI-AODs centered at the AERONET site. Over ocean, the same collocation criteria were selected between Aqua/MODIS and TANSO-CAI. To avoid the remaining cloud noises, the comparisons between TANSO-CAI and AERONET were carried out for the $3 \times 3$ pixels.

\subsubsection{Validation of Retrieved AOD with AERONET}

Figure 6 shows the results of comparisons between CAI-AODs and those from the AERONET sun-photometers (Figure 6a,c-f) and MODIS DB algorithm centered at AERONET sites (Figure 6b) from June 2009 to December 2013 over Northeast Asia [57,58]. In 2009, the CAI-AODs retrieved using the reflectance corrected with JAXA's correction coefficients, were compared with AERONET Level 2 data at 9 sites. In 2010, 2011, and 2013, CAI-AODs retrieved using the reflectance corrected with annual RDFs except for the period from January to March 2010, were compared with AERONET observations at 11 sites. In 2012, CAI-AODs were compared with 244 AERONET data at 48 sites, thanks to Distributed Regional Aerosol Gridded Observation Networks-NE Asia 2012 (DRAGON-NE ASIA 2012) campaign conducted for a three-month period (March-May 2012) in South Korea and Japan [59-61]. The validation sites were described in Table 5.

The comparison with AERONET shows that correlation coefficients (R), linear regression slopes, and the RMSE is 0.74, 0.97, and 0.23 for the entire period, respectively (Figure 6a,c-f) and Table 6). Furthermore, most of the linear regression lines appeared close to the 1:1 line within \pm 0.14 . 
The comparison in 2010 had results closest to the 1:1 line (Figure 6c), with the slope equal to 0.999. In particular, Figure $6 \mathrm{~b}$ shows that the correlation coefficient and RMSE of the MODIS and TANSO-CAI retrievals are 0.855 and 0.186 , respectively. The comparisons between AODs from satellite retrievals were better than those from ground-based AERONET observations, as in Figure 6a,b. Although the validation period in 2009 was shorter than in other years, the amount of data was similar and the results showed the best agreement among the periods compared.

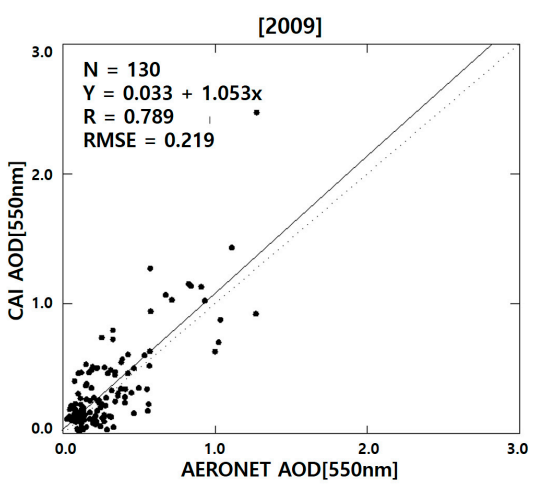

(a)

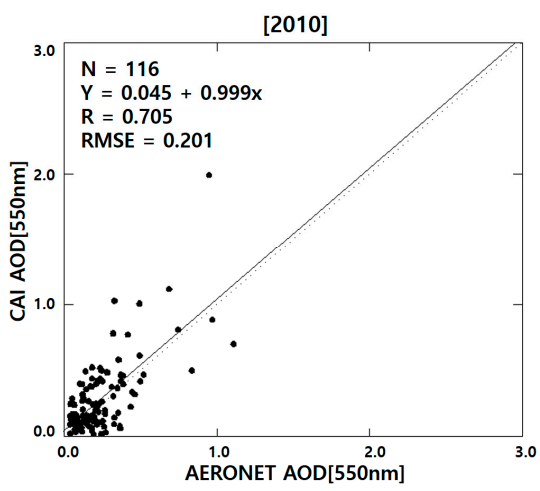

(c)

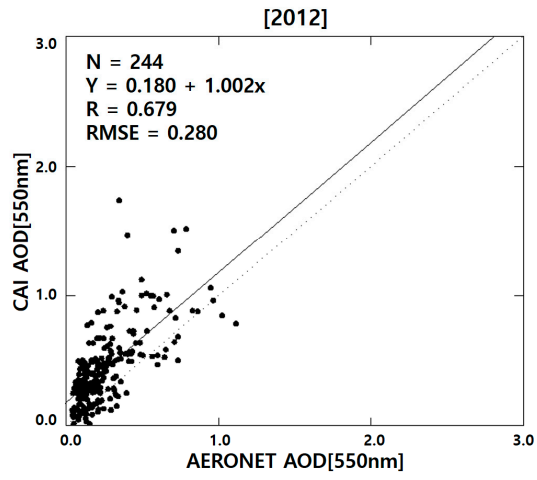

(e)

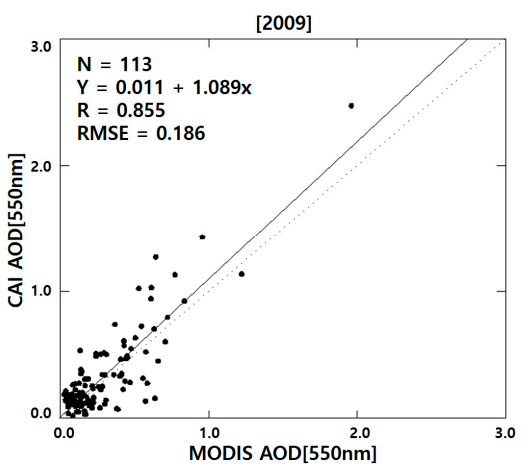

(b)

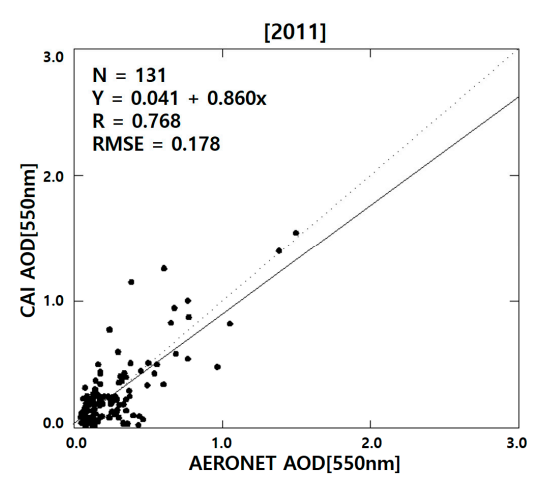

(d)

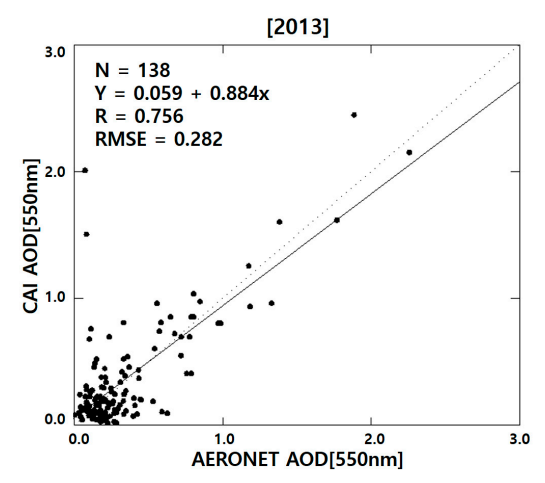

(f)

Figure 6. Comparisons of AODs retrieved from the TANSO-CAI aerosol algorithm with those from the AERONET sun-photometers at $0.55 \mu \mathrm{m}$ over Northeast Asia (a) from June to December, 2009; (b) Comparison of AODs retrieved from the TANSO-CAI aerosol algorithm with those from the Aqua/MODIS (Collection 6) collocated within $0.3^{\circ}$ latitude $\times 0.3^{\circ}$ longitude grid centered AERONET site over the Northeast Asia from June to December 2009; All year comparisons are shown in (c) 2010; (d) 2011; (e) 2012; and (f) 2013. The solid and dashed lines represent the linear regression and one-to-one lines, respectively. 
Table 5. Information of AERONET sites for the validation of retrieved AOD from TANSO-CAI aerosol algorithm [62].

\begin{tabular}{|c|c|c|}
\hline Year & No. & AERONET Sites $\left[112^{\circ}-150^{\circ} \mathrm{E}, 24^{\circ}-50^{\circ} \mathrm{N}\right]$ \\
\hline 2009 & 9 & $\begin{array}{l}\text { Beijing [116.381, 39.977], Gosan_SNU [126.162, 33.292], Gwangju_GIST [126.843, 35.228], Osaka [135.591, } \\
\text { 34.651], Shirahama [135.357, 33.693], Taihu [120.215, 31.421], Ussuriysk [132.163, 43.7], XiangHe [116.962, } \\
\text { 39.754], Xinglong [117.578, 40.396] }\end{array}$ \\
\hline 2010 & 11 & $\begin{array}{l}\text { Baengnyeong [124.63, 7.966], Beijing [116.381, 39.977], Gwangju_GIST [126.843, 35.228], Noto [137.137, } \\
\text { 37.334], NUIST [118.717, 32.206], Osaka [135.591, 34.651], Shirahama [135.357, 33.693], Taihu [120.215, 31.421], } \\
\text { Ussuriysk [132.163, 43.7], XiangHe [116.962, 39.754], Xinglong [117.578, 40.396] }\end{array}$ \\
\hline 2011 & 11 & $\begin{array}{l}\text { Baengnyeong [124.63, 7.966], Beijing [116.381, 39.977], Chiba_University [140.104, 35.625], Gosan_SNU } \\
\text { [126.162, 33.292], Gwangju_GIST [126.843, 35.228], Osaka [135.591, 34.651], Taihu [120.215, 31.421], Ussuriysk } \\
{[132.163,43.7], \text { XiangHe [116.962, 39.754], Xinglong [117.578, 40.396] }}\end{array}$ \\
\hline 2012 & 48 & $\begin{array}{l}\text { Baengnyeong [124.63, 7.966], Beijing [116.381, 39.977], Chiba_University [140.104, 35.625], } \\
\text { DRAGON_Anmyeon [126.33, 36.539], DRAGON_Bokjeong [127.131, 37.457], DRAGON_Fukue } \\
\text { [128.682/32.752], DRAGON_Fukue_2 [128.817/32.672], DRAGON_Fukuoka [130.475,33.524], } \\
\text { DRAGON_GangneungWNU [128.867, 37.771], DRAGON_Guwol [126.724, 37.45], } \\
\text { DRAGON_Gwangju_GIST, [126.843, 35.228] DRAGON_Hankuk_UFS [127.266, 37.339], DRAGON_Kobe } \\
\text { [135.291,34.72], DRAGON_Konju_NU [127.14, 36.471], DRAGON_Konkuk_Univ [127.08, 37.542], } \\
\text { DRAGON_Korea_Univ [127.025, 37.585], DRAGON_Kunsan_NU [126.683, 35.941], DRAGON_Kyoto } \\
\text { [135.781, 35.026], DRAGON_Kyungil_Univ [128.824, 36.072], DRAGON_Mokpo_NU [126.437, 34.913], } \\
\text { DRAGON_Mt_Rokko [135.23, 34.757], DRAGON_Nara [135.828, 34.688], DRAGON_NIER [126.64, 37.569], } \\
\text { DRAGON_Nishiharima [134.336, 35.026], DRAGON_Osaka-North [135.51, 34.774], DRAGON_Osaka-South } \\
\text { [135.504, 34.544], DRAGON_Pusan_NU [129.083, 35.235], DRAGON_Sinjeong [126.859, 37.523], } \\
\text { DRAGON_Soha [126.885, 37.452], DRAGON_Tsukuba [140.12, 36.051], Fukue [128.682, 32.752], } \\
\text { Gangneung_WNU [128.867, 37.77], Gosan_SNU [126.162, 33.292], Hankuk_UFS [127.266, 37.339], Kobe } \\
\text { [135.291, 34.72], Nara [135.828, 34.688], Noto [137.137, 37.334], Osaka [135.591, 34.651], Osaka-North [135.51, } \\
\text { 34.774], Pusan_NU [129.083, 35.235], Seoul_SNU [126.951, 37.458], Shirahama [135.357, 33.693], Taihu } \\
\text { [120.215, 31.421], Ussuriysk [132.163, 43.7], XiangHe [116.962, 39.754], Xinglong [117.578, 40.396], } \\
\text { Yonsei_University [126.935, 37.564] }\end{array}$ \\
\hline 2013 & 11 & $\begin{array}{l}\text { Baengnyeong, Beijing [116.381, 39.977], Gangneung_WNU [128.867, 37.77], Gosan_SNU [126.162, 33.292], } \\
\text { Hankuk_UFS [127.266, 37.339], Noto [137.137, 37.334], Osaka [135.591, 34.651], Seoul_SNU [126.951, 37.458], } \\
\text { Ussuriysk [132.163, 43.7], Yonsei_University [126.935, 37.564] }\end{array}$ \\
\hline
\end{tabular}

Table 6. Statistics for the comparison of AOD retrieved from TANSO-CAI aerosol algorithm and AERONET and Aqua/MODIS (ocean) observations from June 2009 to December 2013.

\begin{tabular}{ccccccc}
\hline Sensor & Result & $\mathbf{2 0 0 9}$ & $\mathbf{2 0 1 0}$ & $\mathbf{2 0 1 1}$ & $\mathbf{2 0 1 2}$ & $\mathbf{2 0 1 3}$ \\
\hline & $\mathrm{N}$ & 113 & 116 & 131 & 244 & 138 \\
& $\mathrm{R}$ & 0.855 & 0.705 & 0.768 & 0.679 & 0.756 \\
AERONET & Slope & 1.089 & 0.999 & 0.860 & 1.002 & 0.884 \\
& y-offset & 0.011 & 0.045 & 0.041 & 0.180 & 0.059 \\
& RMSE & 0.186 & 0.201 & 0.178 & 0.280 & 0.282 \\
\hline & $\mathrm{N}$ & 17944 & 32264 & 26370 & 40929 & 20623 \\
Aqua/MODIS & $\mathrm{R}$ & 0.867 & 0.804 & 0.824 & 0.823 & 0.830 \\
(Ocean) & Slope & 1.254 & 1.203 & 1.240 & 1.132 & 1.302 \\
& y-offset & 0.019 & 0.032 & 0.012 & 0.074 & -0.006 \\
& RMSE & 0.143 & 0.126 & 0.130 & 0.172 & 0.127 \\
\hline
\end{tabular}

In 2009, the monthly RDFs, which were represented by season, were available to correct each reflectance instead of the annual RDFs, as listed in Table 3. These monthly RDF-corrected reflectance in each band improved the accuracy of estimated surface reflectance, and hence aerosol property retrieval, compared to the years with annual RDFs only. This means that the radiometric degradation correction is one of the important factors to determine the accuracy of aerosol retrievals in TANSO-CAI observations.

Even with this effort to adopt monthly RDFs, however, the regression slope in 2009 was slightly higher than the one-to-one line (Figure 6a,b), which is a problem in the calculation of surface reflectance by the minimum reflectance composite method. In general, aerosol retrievals using surface reflectance calculated by minimum reflectance method have a large uncertainty over bright surfaces, whereas they 
remain accurate over dark surfaces. In particular, in spring and late autumn, the accurate calculation of surface reflectance by the minimum reflectance composite method was mainly influenced by rapid vegetation growth and decline, respectively [15]. The results from the TANSO-CAI aerosol algorithm also show lower validation statistics $(\mathrm{R}=0.81 \pm 0.14$, $\mathrm{RMSE}=0.18 \pm 0.14$, and y-offset $=0.12 \pm 0.16$ ) compared with AERONET during these seasons.

Furthermore, frequent snow cover during wintertime and early springtime were one of the error sources in aerosol retrievals. Bright pixels over the snow surface, which were occasionally not removed from the TANSO-CAI aerosol algorithm, can result in overestimated, AODs shown as high CAI-AOD values in Figure 6f. On the other hand, underestimated AOD values tend to spread from the 1:1 line due to the uncertainty of aerosol type selection from LUTs [6,26]. The results for AOD $\leq 0.25$ also indicate low correlation despite the reasonable agreement between all of the retrieved values.

In 2012, the comparison showed the lowest correlation $(R=0.679$, y-offset $=0.180$, and RMSE $=0.280$ ) despite the largest datasets with AERONET (Figure 6e). One can note the same CAI-AOD values at approximately 0.25 and 0.50 , and larger RMSE compared to other years, whereas those of AERONET showed slightly different values. This can be explained by the dense AERONET network in Seoul, Korea, and Osaka, Japan, during the DRAGON-NE ASIA 2012.

Despite the persistence of issues such as reflectance degradation, difficulty in surface reflectance estimation, and strip noises of the sensor, the comparison results showed generally good agreement. In addition, AODs from the TANSO-CAI reflectance corrected with monthly RDFs showed the best agreement with both AERONET and MODIS observations compared to previous studies $[17,63]$.

\subsubsection{Validation of Retrieved AOD with MODIS over Ocean}

Figure 7 shows the annual scatterplot of CAI-AOD retrievals at $0.55 \mu \mathrm{m}$ over ocean collocated with Aqua/MODIS (C6) Level 2 DT products from June 2009 to December 2013. The dataset collocated for the comparison was over 20,000 each year, except for 2009, when the comparison period was shorter. The comparisons were in nine-pixel averages of approximately $30 \mathrm{~km} \times 30 \mathrm{~km}$ for both MODIS and TANSO-CAI retrievals. The colored pixels represent an AOD frequency with a bin size of 0.03 . The black solid and dashed lines represent the linear regression line and a one-to-one line, respectively. These represent the correlation coefficients (R) of $0.830 \pm 0.023$ and the RMSE of $0.140 \pm 0.019$ for the period of five years. However, the regression line slopes of $1.226 \pm 0.063$ were relatively higher than those between TANSO-CAI retrievals and AERONET observations. Although CAI-AODs tend to be slightly overestimated compared to MODIS products, they were in good agreement over ocean during the entire period studied. It was estimated that surface reflectance, calculated over a long search window (target day \pm 11 paths), was relatively lower than that of MODIS, and thus resulted in the overestimation of AODs. The current algorithm for ocean surface reflectance did not take into account wind speeds, which needs to be addressed in the near future.

The comparison of MODIS-AODs and CAI-AODs over ocean showed better correlation than those over land. Over ocean, CAI-AODs showed similar correlation (approximately $\mathrm{R}=0.81, \mathrm{RMSE}=$ 0.18 ) without seasonal variation, although that of autumn is the best (approximately $\mathrm{R}=0.87, \mathrm{RMSE}=$ 0.13). Over land, however, CAI-AODs showed the best correlation in autumn (approximately $R=0.70$, RMSE $=0.28$ ) and those in summer and winter showed the even lower correlation (approximately $R=$ 0.65 , RMSE $=0.24$ ) by rapid vegetation changes. In particular, the linear regression slope varied in the range of $0.66-1.42$ by season (figures not shown here). The CAI-AODs tend to overestimate the AERONET values in all seasons except when AODs are less than 0.2. The CAI-AODs in spring show the highest RMSE (approximately 0.38) than those other seasons. However, CAI-AODs show generally the good correlation with those of Aqua/MODIS DT and DB at AERONET sites (average $0.3^{\circ} \times 0.3^{\circ}$ ) for all seasons.

Despite of these restrictions, the results in 2009 had the highest correlation with both ground-based (AERONET) and satellite (MODIS) measurements (Figures 6 and 7), which can be explained by the seasonal RDFs in 2009. To test this effect quantitatively, aerosol properties were retrieved using 
the annual RDFs of Kuze et al. [34] and seasonal RDFs of JAXA, and compared with those of MODIS. Figure 8 shows the comparisons between AODs derived from the Aqua/MODIS C6 DT aerosol algorithm and CAI-AODs (a) with annual RDFs and (b) seasonal RDFs over ocean from June to December 2009. The results of Figure $8 b$ were significantly better than those of Figure $8 a$, as demonstrated by the increase in correlation coefficient $(\mathrm{R})$ from 0.768 to 0.867 ; the RMSE decreased from 0.223 to 0.142 , and the y-offset was close to zero from 0.116 to 0.019 . The comparison results showed an improvement of approximately $13 \%$ and $44 \%$ for the correlation coefficient and RMSE in 2009, respectively (Figure 8). This indicates that correction of radiometric degradation is one of the essential factors for accurate retrievals of aerosol properties.

(a)

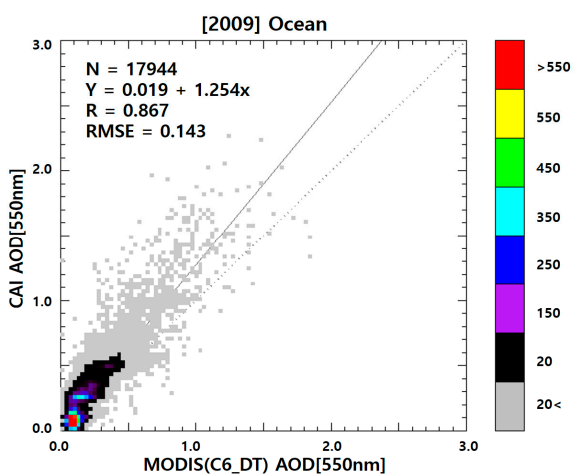

(c)

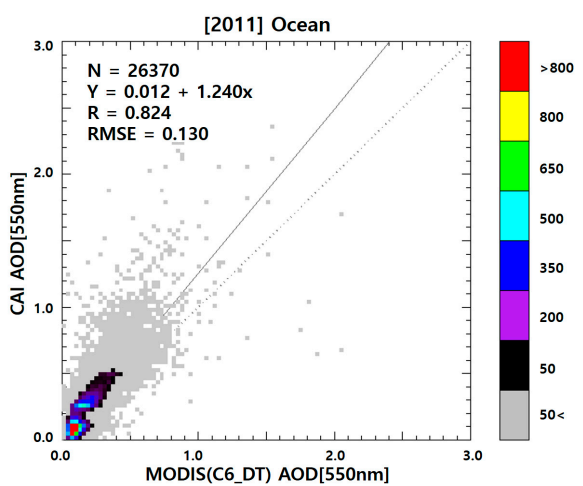

(e)

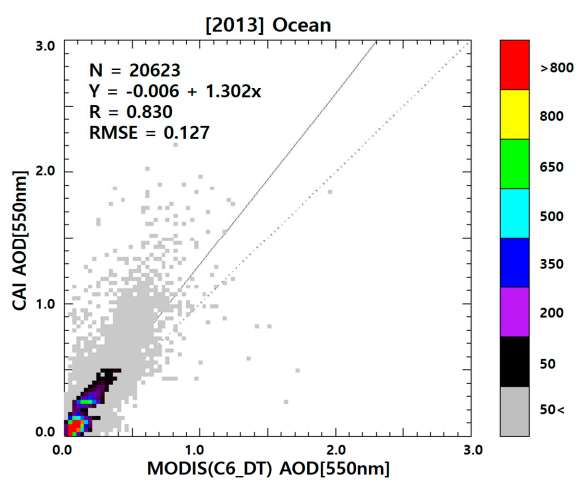

(b)

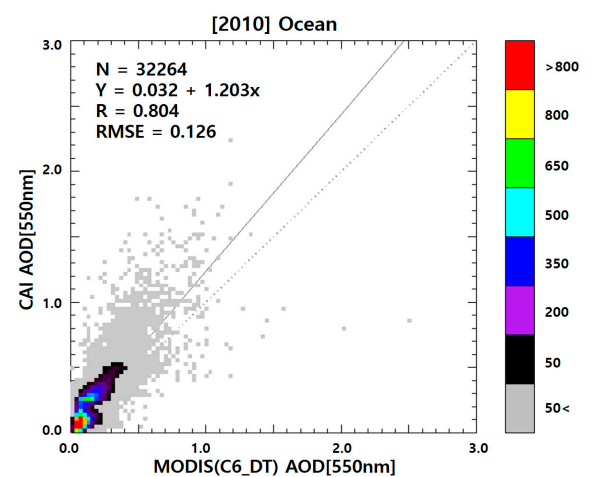

(d)



Figure 7. Comparisons of AOD retrieved from the TANSO-CAI aerosol algorithm with those from Aqua/MODIS (collection 6) dark target algorithm over ocean (a) from June to December 2009; the whole of (b) 2010; (c) 2011; (d) 2012; and (e) 2013. The colored pixels represent a frequency number with a bin size of 0.03 AOD. The black solid and dashed lines are the linear regression and the one-to-one lines, respectively.

For the seasonal difference of AODs retrieved by AERONET, TANSO-CAI, and Aqua/MODIS DT, the frequency number with a bin size of 0.2 are analyzed, as shown in Figure 9 . The datasets are 
collocated at AEROENT sites, where AODs of Aqua/MODIS and TANSO-CAI were averaged by $0.3^{\circ}$ grid box. Each frequency of their distribution showed the total number of AODs of AEROENT (black), TANSO-CAI (cyan), and Aqua/MODIS DT (blue). CAI-AODs show similar distribution with those of AERONET and Aqua/MODIS, but the frequency ranged from 0 to 0.2 show different features of all seasons. In spring and summer, CAI-AODs below 0.2 show larger frequencies than those of AERONET and Aqua/MODIS. In autumn and winter, CAI-AOD below 0.2 shows the opposite tendency. However, total CAI-AODs below 0.4 show the similar frequency. This means that the CAI-AODs retrieved tend to be smaller than those from other satellite algorithm when AOD is below 0.4. This can be attributed to the larger influence of the surface reflectance and type selection. However, it is difficult to conclude in summer when the dataset for the comparison is too small because of the rainy season.

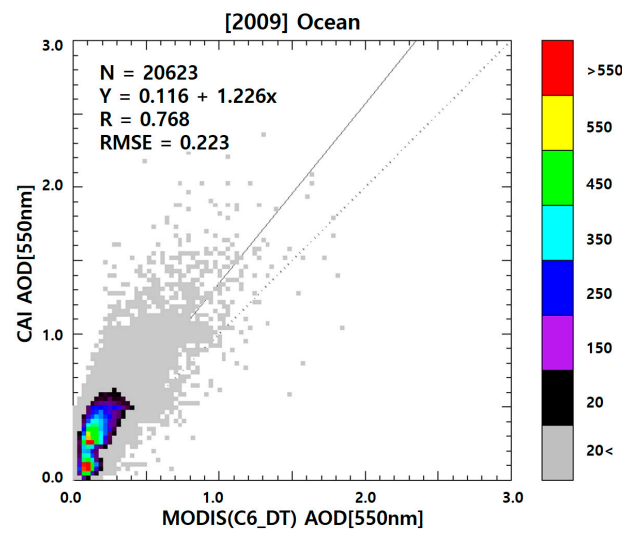

(a)

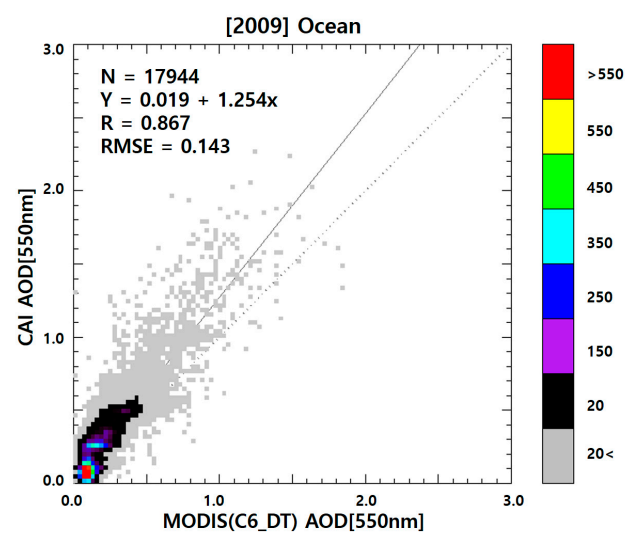

(b)

Figure 8. Comparisons of AOD retrieved from the TANSO-CAI aerosol algorithm with those from Aqua/MODIS (collection 6) over ocean (a) with RDFs by Kuze et al. [34]; (b) with RDFs by JAXA's MODIS correction result from June to December 2009. The colored pixels represent a frequency number with a bin size of 0.03 AOD. The black solid and dashed lines are the linear regression and one-to-one lines, respectively.

(a)

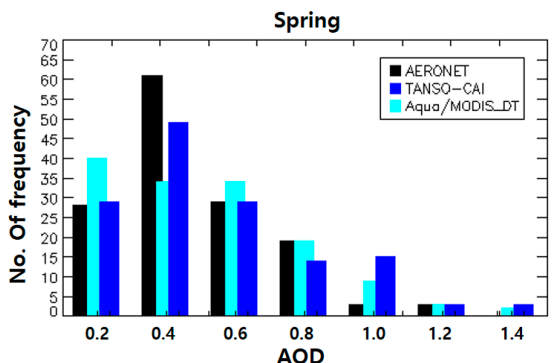

(c)

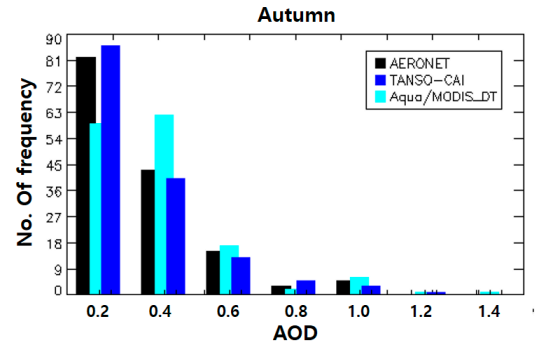

(b)



(d)

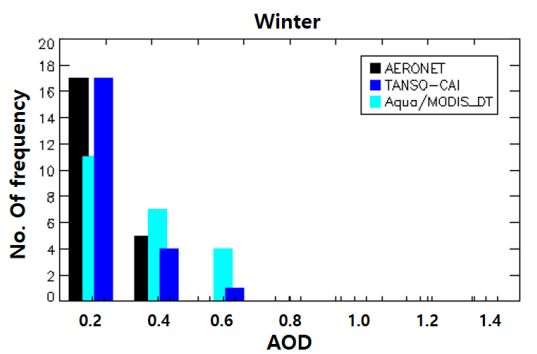

Figure 9. Frequency number of AODs retrieved by AERONET, Aqua/MODIS, and TANSO-CAI measurements at AERONET sites from June 2009 to December 2013 in (a) spring; (b) summer; (c) autumn; and (d) winter. Where, AODs of Aqua/MODIS and TANSO-CAI were averaged by $0.3^{\circ}$ grid box. 


\section{Summary and Conclusions}

An aerosol retrieval algorithm was developed for the TANSO-CAI on board the GOSAT. The TANSO-CAI algorithm can retrieve aerosol properties in the grid resolution of $0.1^{\circ}$ (approximately $10 \mathrm{~km}$ ) with the LUT approach. Here, we suggested a new method using NDVI and R(band 2)/R(band 3 ) for the cloud mask, and a threshold using surface reflectance $(>0.101)$ at band 2 , for the elimination of turbid water over ocean. The retrieval grid boxes and sun glint mask used in the MODIS aerosol algorithm $[6,29]$ were also adopted to reduce the errors caused by bad reflectance data. To calculate the surface reflectance, the minimum reflectance composite method was used with a search window containing the same 23 paths before and after a target day, which is to avoid the stripes at each band. Reflectance difference tests between UV and VIS channels for absorptivity were also used to select aerosol types from LUT.

The aerosol properties were retrieved over Northeast Asia from the TANSO-CAI algorithm, for the long period from June 2009 to December 2013. The retrieved AODs were compared with AERONET and MODIS products over land and ocean. This is the first study that compared both ground and satellite-based observations for a period of nearly five years to obtain the aerosol properties from the TANSO-CAI. Furthermore, comparisons of AODs between AERONET and TANSO-CAI showed improvement compared to previous studies $[17,63]$. The results of AERONET and TANSO-CAI showed a correlation coefficient of $0.739 \pm 0.046$, RMSE of $0.232 \pm 0.047$, and regression slope of $0.960 \pm 0.083$ for the entire period. In addition, the comparison of MODIS and TANSO-CAI over ocean showed improved agreement, with correlation coefficient of $0.830 \pm 0.047$, RMSE of $0.140 \pm$ 0.019 , and regression slope of $1.226 \pm 0.063$ for the entire period. The regression line slopes between TANSO-CAI and MODIS were higher by approximately $15-30 \%$ than the results over ocean, which showed a slope very close to 1 . However, the comparison with MODIS and TANSO-CAI over land are still poorer $(\mathrm{R}=0.667 \pm 0.017$, $\mathrm{RMSE}=0.403 \pm 0.105$, slope $=0.771 \pm 0.064)$ than those over ocean. We are continuously evaluating the AOD over land to improve the TANSO-CAI aerosol algorithm.

The frequency of CAI-AOD below 0.2 is approximately $30 \%$ of the total both after applying seasonal and annual RDFs. The contribution of the background marine AOD for clear days loading may be estimated to low over Northeast Asia. However, CAI-AODs show different tendency by season over ocean when AODs is lower than 0.2. In spring and summer, CAI-AODs below 0.2 show larger frequencies than AERONET and Aqua/MODIS. This means that the selected dark pixel for the surface reflectance is higher than that of Aqua/MODIS over ocean. In particular, it is difficult to determine a dark pixel in a poor composite in summer because of the included rainy season. In contrast, CAI-AODs below 0.2 show overestimated values compared to those of AERONET and Aqua/MODIS. Even though CAI-AODs below 0.4 show the similar frequency, it means that the TANSO-CAI aerosol algorithm is still not ideal for calculating the surface reflectance over ocean. When the comparisons were done for AODs above 0.2 , the linear regression slope became closer to 1 , showing some improvements.

The CAI-AODs tend to overestimate the AERONET values in all seasons except for when AOD is less than 0.2. The reasons for this are as follows. First, it can be explained by the difference in surface reflectance between TANSO-CAI and other measurements. As mentioned in Section 2.6, the 30-day time window is reasonable when the composite method is considered for the calculation of surface reflectance. However, as GOSAT has a three-day revisit schedule, the TANSO-CAI aerosol algorithm extended the search window of the 23 paths instead of the previous 30-day. Therefore, the surface reflectance calculated from the TANSO-CAI aerosol algorithm is slightly lower than that obtained via Aqua/MODIS or other instruments. However, it is difficult to find clear pixels when a search window has fewer than 23 paths, resulting in a relatively high surface reflectance. Second, TANSO-CAI aerosol algorithm has cloud masking over land. TANSO-CAI has only four bands without the required IR wavelengths for the removal of clouds from TANSO-CAI measurements. It is also difficult to mask the cloud signals in the aerosol retrievals. Over ocean, we suggested the combined method with NDVI and $\mathrm{R}$ (band 2)/R(band 3); however, this method experiences difficulty in distinguishing between 
clouds and heavy dust, although it is very effective at removing thin clouds and cloud edges. However, this concept is not suitable for aerosol retrievals over land because the NDVI is affected by the rapid change of vegetation condition. Third, TANSO-CAI cannot correct reflectance because the irregular radiometric degradation reaches approximately $20 \%$, which affects aerosol type selection from LUTs using a reflectance difference test between band 1 and 2 .

The annual and seasonal RDFs derived from the comparison with Aqua/MODIS products were applied to improve the accuracy of the TANSO-CAI aerosol algorithm. According to Kuze et al. [23,33,34], the TANSO-CAI spectra showed irregular radiometric degradation that was larger than other satellite observations through the VCC. During the two initial years, observed degradations reached approximately $20 \%$ at bands 1 and 4 . As a result, we found that reflectance correction by more accurate RDFs improved the accuracy of retrieved surface reflectance and aerosol properties. In the future, with more accurate RDFs by month or season for the entire period, the accuracy of the retrieval can be improved.

Although the coverage of aerosol retrievals from TANSO-CAI was limited compared to other satellites such as geostationary satellites or polar-orbit satellites of daily global coverage, these aerosol products still provide valuable information for $\mathrm{CO}_{2}$ retrieval using TANSO-FTS measurements. In fact, our aerosol properties at $0.76 \mu \mathrm{m}$ have been used as inputs for the Yonsei Carbon retrieval (YCAR) algorithm instead of those by model or climatology. These have also improved the data coverage and accuracy of $\mathrm{CO}_{2}$ retrieval from TANSO-FTS measurements [25].

Acknowledgments: We thank the GOSAT project office for providing access to the GOSAT-CAI data products for this work based on their RA 2, and National Institute of Meteorological Research (NIMR) for data support used in this work. We would like to thank the AERONET network and the principal investigators, as well as their staff, for establishing and maintaining the AERONET sites used in this work. This subject is supported by the Korea Ministry of Environment (MOE) as "Public Technology Program based on Environmental Policy (2017000160001)".

Author Contributions: For research articles with several authors, a short paragraph specifying their individual contributions must be provided. The following statements should be used "Sanghee Lee worked on the algorithm development and performed the experiments.; Mijin Kim, Myungje Choi, and Ukkyo Jeong advised to design the experiments; Sujung Go, HyunKwang Lim, and Jung-Hyun Kim contributed to collect data; Akihiko Kuze and Kei Shiomi provided updated factors to improve the algorithm; Tae-Young Goo contributed data and materials; Sanghee Lee and Jhoon Kim analyzed the results and wrote the paper." Authorship must be limited to those who have contributed substantially to the work reported.

Conflicts of Interest: The authors declare no conflict of interest.

\section{References}

1. IPCC. Climate Change 2013: The Physical Science Basis. Contribution of Working Group I to the Fifth Assessment Report of the Intergovernmental Panel on Climate Change; Cambridge University Press: Cambridge, UK and New York, NY, USA, 2013; p. 1535.

2. Lee, J.; Kim, J.; Song, C.H.; Ryu, J.-H.; Ahn, Y.-H.; Song, C. Algorithm for retrieval of aerosol optical properties over the ocean from the geostationary ocean color imager. Remote Sens. Environ. 2010, 114, 1077-1088. [CrossRef]

3. Higurashi, A.; Nakajima, T. Detection of aerosol types over the East China Sea near Japan from four-channel satellite data. Geophys. Res. Lett. 2002, 29, 1836. [CrossRef]

4. Kim, J.; Lee, J.; Lee, H.C.; Higurashi, A.; Takemura, T.; Song, C.H. Consistency of the aerosol type classification from satellite remote sensing during the atmospheric brown cloud-East Asia regional experiment campaign. J. Geophys. Res. Atmos. 2007, 112, D22S33. [CrossRef]

5. Levy, R.C.; Remer, L.A.; Tanré, D.; Kaufman, Y.J.; Ichoku, C.; Holben, B.N.; Livingston, J.M.; Russell, P.B.; Maring, H. Evaluation of the moderate-resolution imaging spectroradiometer (MODIS) retrievals of dust aerosol over the ocean during pride. J. Geophys. Res. Atmos. 2003, 108, 8594. [CrossRef]

6. Remer, L.A.; Kaufman, Y.; Tanré, D.; Mattoo, S.; Chu, D.; Martins, J.V.; Li, R.-R.; Ichoku, C.; Levy, R.; Kleidman, R. The MODIS aerosol algorithm, products, and validation. J. Atmos. Sci. 2005, 62, 947-973. [CrossRef] 
7. Govaerts, Y.; Wagner, S.; Lattanzio, A.; Watts, P. Joint retrieval of surface reflectance and aerosol optical depth from MSG/SEVIRI observations with an optimal estimation approach: 1. Theory. J. Geophys. Res. Atmos. 2010, 115, D02203. [CrossRef]

8. Wagner, S.; Govaerts, Y.; Lattanzio, A. Joint retrieval of surface reflectance and aerosol optical depth from MSG/SEVIRI observations with an optimal estimation approach: 2. Implementation and evaluation. J. Geophys. Res. Atmos. 2010, 115, D02204. [CrossRef]

9. Jeong, U.; Kim, J.; Ahn, C.; Torres, O.; Liu, X.; Bhartia, P.K.; Spurr, R.J.; Haffner, D.; Chance, K.; Holben, B.N. An optimal-estimation-based aerosol retrieval algorithm using omi near-UV observations. Atmos. Chem. Phys. 2016, 16, 177-193. [CrossRef]

10. Kuze, A.; Suto, H.; Nakajima, M.; Hamazaki, T. Thermal and near infrared sensor for carbon observation fourier-transform spectrometer on the greenhouse gases observing satellite for greenhouse gases monitoring. Appl. Opt. 2009, 48, 6716-6733. [CrossRef] [PubMed]

11. Yokota, T.; Yoshida, Y.; Eguchi, N.; Ota, Y.; Tanaka, T.; Watanabe, H.; Maksyutov, S. Global concentrations of $\mathrm{CO}_{2}$ and $\mathrm{CH}_{4}$ retrieved from GOSAT: First preliminary results. Sola 2009, 5, 160-163. [CrossRef]

12. Ishida, H.; Nakjima, T.Y.; Yokota, T.; Kikuchi, N.; Watanabe, H. Investigation of GOSAT TANSO-CAI cloud screening ability through an intersatellite comparison. J. Appl. Meteorol. Climatol. 2011, 50, 1571-1586. [CrossRef]

13. Frankenberg, C.; Pollock, R.; Lee, R.; Rosenberg, R.; Blavier, J.-F.; Crisp, D.; O’Dell, C.; Osterman, G.; Roehl, C.; Wennberg, P. The Orbiting Carbon Observatory (OCO-2): Spectrometer performance evaluation using pre-launch direct sun measurements. Atmos. Meas. Tech. 2015, 8, 301-313. [CrossRef]

14. Bösch, H.; Brown, L.; Castano, R.; Christi, M.; Connor, B.; Crisp, D.; Eldering, A.; Fisher, B.; Frankenberg, C.; Gunson, M. Orbiting Carbon Observatory (OCO)-2 level 2 Full Physics Retrieval Algorithm Theoretical Basis Document; NASA JPL: Pasadena, CA, USA, 2015.

15. Kaufman, Y.; Tanré, D.; Remer, L.A.; Vermote, E.; Chu, A.; Holben, B. Operational remote sensing of tropospheric aerosol over land from EOS moderate resolution imaging spectroradiometer. J. Geophys. Res. Atmos. 1997, 102, 17051-17067. [CrossRef]

16. Sayer, A.; Hsu, N.; Bettenhausen, C.; Jeong, M.J. Validation and uncertainty estimates for MODIS Collection 6 “Deep Blue" aerosol data. J. Geophys. Res. Atmos. 2013, 118, 7864-7872. [CrossRef]

17. Fukuda, S.; Nakajima, T.; Takenaka, H.; Higurashi, A.; Kikuchi, N.; Nakajima, T.Y.; Ishida, H. New approaches to removing cloud shadows and evaluating the $380 \mathrm{~nm}$ surface reflectance for improved aerosol optical thickness retrievals from the GOSAT/TANSO-cloud and aerosol imager. J. Geophys. Res. Atmos. 2013, 118, 13520-13531. [CrossRef]

18. Shi, C.; Nakajima, T.; Hashimoto, M. Simultaneous retrieval of aerosol optical thickness and chlorophyll concentration from multiwavelength measurement over East China Sea. J. Geophys. Res. Atmos. 2016, 121, 14084-14101. [CrossRef]

19. Hashimoto, M.; Nakajima, T.; Morimoto, S.; Takenaka, H. Development of a generalized algorithm of satellite remote sensing using multi-wavelength and multi-pixel information (MWP method) for aerosol properties by satellite-borne imager. In Proceedings of the AGU Fall Meeting, San Francisco, CA, USA, 15-19 December 2014.

20. Yoshida, Y.; Ota, Y.; Eguchi, N.; Kikuchi, N.; Nobuta, K.; Tran, H.; Morino, I.; Yokota, T. Retrieval algorithm for $\mathrm{CO}_{2}$ and $\mathrm{CH}_{4}$ column abundances from short-wavelength infrared spectral observations by the greenhouse gases observing satellite. Atmos. Meas. Tech. 2011, 4, 717-734. [CrossRef]

21. Yoshida, Y.; Kikuchi, N.; Morino, I.; Uchino, O.; Oshchepkov, S.; Bril, A.; Saeki, T.; Schutgens, N.; Toon, G.; Wunch, D. Improvement of the retrieval algorithm for GOSAT swir $\mathrm{XCO}_{2}$ and $\mathrm{XCH}_{4}$ and their validation using tccon data. Atmos. Meas. Tech. 2013, 6, 1533-1547. [CrossRef]

22. Kina, T.; Shiomi, K.; Kawakami, S.; Mitomi, Y.; Yoshida, M.; Higuchi, R.; Sekio, N.; Kataoka, F. Results of calibration for GOSAT TANSO. Sahara 2010, 1, 91-93.

23. Kuze, A.; Suto, H.; Shiomi, K. Update on GOSAT TANSO-FTS performance, operations, and data products after more than 6 years in space. Atmos. Meas. Tech. 2016, 9, 2445-2461. [CrossRef]

24. Kim, W.; Kim, J.; Jung, Y.; Boesch, H.; Lee, H.; Lee, S.; Goo, T.-Y.; Jeong, U.; Kim, M.; Cho, C.-H. Retrieving $\mathrm{XCO}_{2}$ from GOSAT FTS over East Asia using simultaneous aerosol information from CAI. Remote Sens. 2016, 8, 994. [CrossRef] 
25. Jung, Y.; Kim, J.; Kim, W.; Boesch, H.; Lee, H.; Cho, C.; Goo, T.-Y. Impact of aerosol property on the accuracy of a $\mathrm{CO}_{2}$ retrieval algorithm from satellite remote sensing. Remote Sens. 2016, 8, 322. [CrossRef]

26. Dubovik, O.; Holben, B.; Eck, T.F.; Smirnov, A.; Kaufman, Y.J.; King, M.D.; Tanré, D.; Slutsker, I. Variability of absorption and optical properties of key aerosol types observed in worldwide locations. J. Atmos. Sci. 2002, 59, 590-608. [CrossRef]

27. Lee, J.; Kim, J.; Yang, P.; Hsu, N. Improvement of aerosol optical depth retrieval from MODIS spectral reflectance over the global ocean using new aerosol models archived from AERONET inversion data and tri-axial ellipsoidal dust database. Atmos. Chem. Phys. 2012, 12, 7087-7102. [CrossRef]

28. Higurashi, A.; Nakajima, T. Development of a two-channel aerosol retrieval algorithm on a global scale using NOAA AVHRR. J. Atmos. Sci. 1999, 56, 924-941. [CrossRef]

29. Levy, R.C.; Remer, L.A.; Mattoo, S.; Vermote, E.F.; Kaufman, Y.J. Second-generation operational algorithm: Retrieval of aerosol properties over land from inversion of moderate resolution imaging spectroradiometer spectral reflectance. J. Geophys. Res. Atmos. 2007, 112, D13211. [CrossRef]

30. Nakajima, T.; Tanaka, M. Algorithms for radiative intensity calculations in moderately thick atmospheres using a truncation approximation. J. Quant. Spectrosc. Radiat. Transf. 1988, 40, 51-69. [CrossRef]

31. Choi, M.; Kim, J.; Lee, J.; Kim, M.; Park, Y.-J.; Jeong, U.; Kim, W.; Hong, H.; Holben, B.; Eck, T.F. GOCI yonsei aerosol retrieval (YAER) algorithm and validation during the DRAGON-NE Asia 2012 campaign. Atmos. Meas. Tech. 2016, 9, 1377-1398. [CrossRef]

32. Nakajima, T.; Tanaka, M. Matrix formulations for the transfer of solar radiation in a plane-parallel scattering atmosphere. J. Quant. Spectrosc. Radiat. Transf. 1986, 35, 13-21. [CrossRef]

33. Kuze, A.; Suto, H.; Shiomi, K.; Urabe, T.; Nakajima, M.; Yoshida, J.; Kawashima, T.; Yamamoto, Y.; Kataoka, F. Level 1 algorithms for TANSO on GOSAT: Processing and on-orbit calibrations. Atmos. Meas. Tech. Discuss. 2012, 5, 2959-3018. [CrossRef]

34. Kuze, A.; Taylor, T.E.; Kataoka, F.; Bruegge, C.J.; Crisp, D.; Harada, M.; Helmlinger, M.; Inoue, M.; Kawakami, S.; Kikuchi, N. Long-term vicarious calibration of GOSAT short-wave sensors: Techniques for error reduction and new estimates of radiometric degradation factors. IEEE Trans. Geosci. Remote Sens. 2014, 52, 3991-4004. [CrossRef]

35. Someya, Y.; Imasu, R.; Saitoh, N.; Ota, Y.; Shiomi, K. A development of cloud top height retrieval using thermal infrared spectra observed with GOSAT and comparison with CALIPSO data. Atmos. Meas. Tech. 2016, 9, 1981-1992. [CrossRef]

36. GOSAT User Interface Gateway. Available online: https://data2.gosat.nies.go.jp/index_en.html (accessed on 19 April 2017).

37. GOSAT/TANSO Calibration and Validation Plan and Overview of Processing Algorithms. Available online: www.gosat.nies.go.jp/newpdf/11RApdf_en/5_GOSAT_2RA_B_en.pdf (accessed on 19 April 2017).

38. Martins, J.V.; Tanré, D.; Remer, L.; Kaufman, Y.; Mattoo, S.; Levy, R. Modis cloud screening for remote sensing of aerosols over oceans using spatial variability. Geophys. Res. Lett. 2002, 29, MOD4-1-MOD4-4. [CrossRef]

39. Pettorelli, N.; Vik, J.O.; Mysterud, A.; Gaillard, J.-M.; Tucker, C.J.; Stenseth, N.C. Using the satellite-derived ndvi to assess ecological responses to environmental change. Trends Ecol. Evol. 2005, 20, 503-510. [CrossRef] [PubMed]

40. Anyamba, A.; Tucker, C. Analysis of sahelian vegetation dynamics using NOAA-AVHRR NDVI data from 1981-2003. J. Arid Environ. 2005, 63, 596-614. [CrossRef]

41. Baldi, G.; Nosetto, M.D.; Aragón, R.; Aversa, F.; Paruelo, J.M.; Jobbágy, E.G. Long-term satellite NDVI data sets: Evaluating their ability to detect ecosystem functional changes in South America. Sensors 2008, 8, 5397-5425. [CrossRef] [PubMed]

42. Wang, Y.; Wang, J.; Levy, R.C.; Xu, X.; Reid, J.S. MODIS retrieval of aerosol optical depth over turbid coastal water. Remote Sens. 2017, 9, 595. [CrossRef]

43. Remer, L.; Mattoo, S.; Levy, R.; Munchak, L. MODIS $3 \mathrm{~km}$ aerosol product: Algorithm and global perspective. Atmos. Meas. Tech. 2013, 6, 1829. [CrossRef]

44. Remer, L.; Mattoo, S.; Levy, R.; Heidinger, A.; Pierce, R.; Chin, M. Retrieving aerosol in a cloudy environment: Aerosol product availability as a function of spatial resolution. Atmos. Meas. Tech. 2012, 5, 1823. [CrossRef]

45. Kuze, A.J. (Earth Observation Research Center, Japan Aerospace Exploration Agency, Tsukuba, Japan). Personal communication, 2015. 
46. Wang, J.; Xu, X.; Spurr, R.; Wang, Y.; Drury, E. Improved algorithm for MODIS satellite retrievals of aerosol optical thickness over land in dusty atmosphere: Implications for air quality monitoring in China. Remote Sens. Environ. 2010, 114, 2575-2583. [CrossRef]

47. De Graaf, M.; Stammes, P.; Torres, O.; Koelemeijer, R. Absorbing aerosol index: Sensitivity analysis, application to GOME and comparison with TOMS. J. Geophys. Res. Atmos. 2005, 110, D01201. [CrossRef]

48. Torres, O.; Bhartia, P.; Herman, J.; Sinyuk, A.; Ginoux, P.; Holben, B. A long-term record of aerosol optical depth from TOMS observations and comparison to aeronet measurements. J. Atmos. Sci. 2002, 59, 398-413. [CrossRef]

49. Torres, O.; Bhartia, P.; Herman, J.; Ahmad, Z.; Gleason, J. Derivation of aerosol properties from satellite measurements of backscattered ultraviolet radiation: Theoretical basis. J. Geophys. Res. Atmos. 1998, 103, 17099-17110. [CrossRef]

50. Herman, J.; Bhartia, P.; Torres, O.; Hsu, C.; Seftor, C.; Celarier, E. Global distribution of UV-absorbing aerosols from nimbus 7/TOMS data. J. Geophys. Res. Atmos. 1997, 102, 16911-16922. [CrossRef]

51. Hsu, N.C.; Herman, J.R.; Gleason, J.; Torres, O.; Seftor, C. Satellite detection of smoke aerosols over a snow/ice surface by TOMS. Geophys. Res. Lett. 1999, 26, 1165-1168. [CrossRef]

52. Go, S.; Kim, M.; Kim, J.; Park, S.S.; Jeong, U.; Choi, M. Detection of absorbing aerosol using single near-UV radiance measurements from a cloud and aerosol imager. Remote Sens. 2017, 9, 378. [CrossRef]

53. Lee, J.; Kim, J.; Lee, Y.G. Simultaneous retrieval of aerosol properties and clear-sky direct radiative effect over the global ocean from MODIS. Atmos. Environ. 2014, 92, 309-317. [CrossRef]

54. Yu, H.; Kaufman, Y.; Chin, M.; Feingold, G.; Remer, L.; Anderson, T.; Balkanski, Y.; Bellouin, N.; Boucher, O.; Christopher, S. A review of measurement-based assessments of the aerosol direct radiative effect and forcing. Atmos. Chem. Phys. 2006, 6, 613-666. [CrossRef]

55. Remer, L.A.; Kaufman, Y.J. Aerosol direct radiative effect at the top of the atmosphere over cloud free ocean derived from four years of MODIS data. Atmos. Chem. Phys. 2006, 6, 237-253. [CrossRef]

56. Levy, R.C.; Remer, L.A.; Kleidman, R.G.; Mattoo, S.; Ichoku, C.; Kahn, R.; Eck, T. Global evaluation of the collection 5 MODIS dark-target aerosol products over land. Atmos. Chem. Phys. 2010, 10, 10399-10420. [CrossRef]

57. Holben, B.; Eck, T.; Slutsker, I.; Tanre, D.; Buis, J.; Setzer, A.; Vermote, E.; Reagan, J.; Kaufman, Y.; Nakajima, T. Aeronet-A federated instrument network and data archive for aerosol characterization. Remote Sens. Environ. 1998, 66, 1-16. [CrossRef]

58. Hsu, N.; Jeong, M.J.; Bettenhausen, C.; Sayer, A.; Hansell, R.; Seftor, C.; Huang, J.; Tsay, S.C. Enhanced deep blue aerosol retrieval algorithm: The second generation. J. Geophys. Res. Atmos. 2013, 118, 9296-9315. [CrossRef]

59. Seo, S.; Kim, J.; Lee, H.; Jeong, U.; Kim, W.; Holben, B.; Kim, S.-W.; Song, C.; Lim, J. Estimation of PM 10 concentrations over seoul using multiple empirical models with AERONET and MODIS data collected during the DRAGON-Asia campaign. Atmos. Chem. Phys. 2015, 15, 319-334. [CrossRef]

60. FIELD CAMPAIGN_Distributed Regional Aerosol Gridded Observation Networks-Asia 2012. Available online: https:/ /aeronet.gsfc.nasa.gov/new_web/DRAGON-Asia_2012_Japan_South_Korea.html (accessed on 19 April 2017).

61. Holben, B.N.; Kim, J.; Sano, I.; Mukai, S.; Eck, T.F.; Giles, D.M.; Schafer, J.S.; Sinyuk, A.; Slutsker, I.; Smirnov, A.; et al. An overview of meso-scale aerosol processes, comparison and validation studies from DRAGON networks. Atmos. Chem. Phys. Discuss. 2017. in review. [CrossRef]

62. Aeronet Sites Information: Aeronet. Available online: https://aeronet.gsfc.nasa.gov/ (accessed on 19 April 2017).

63. Kamei, A.; Sawada, Y.; Oishi, Y.; Yokota, Y.; Murakami, K.; Matsunaga, T. Assessment of gosat cai aerosol products using aqua modis data. In Proceedings of the 57th RSSJ, Ebetsu, Japan, 21-22 November 2014.

(C) 2017 by the authors. Licensee MDPI, Basel, Switzerland. This article is an open access article distributed under the terms and conditions of the Creative Commons Attribution (CC BY) license (http:// creativecommons.org/licenses/by/4.0/). 